\title{
Crossing Networks and Dealer Markets: Competition and Performance
}

\author{
TERRENCE HENDERSHOTT and HAIM MENDELSON*
}

\begin{abstract}
This paper studies the interaction between dealer markets and a relatively new form of exchange, passive crossing networks, where buyers and sellers trade directly with one another. We find that the crossing network is characterized by both positive ("liquidity") and negative ("crowding") externalities, and we analyze the effects of its introduction on the dealer market. Traders who use the dealer market as a "market of last resort" can induce dealers to widen their spread and can lead to more efficient subsequent prices, but traders who only use the crossing network can provide a counterbalancing effect by reducing adverse selection and inventory holding costs.
\end{abstract}

Competition Between exchanges for order flow is a growing phenomenon in financial markets. From London to Paris to Tel Aviv, exchanges and trading systems are introducing new trading mechanisms that compete for order flow. In the United States, the SEC promulgated new rules that redefine the regulation of Alternative Trading Systems and intensify the competition between existing exchanges and new electronic markets. Indeed, new electronic trading venues are cited as the reason for a decline in the value of seats on major exchanges, even though trading volumes are growing rapidly.

What will be the impact of new trading mechanisms on market participants and on existing dealer markets (DMs)? In this paper we study the effect of introducing a passive call market that competes with an existing traditional DM. The DM is based on competing market makers as in Nasdaq, the London Stock Exchange, the Foreign Exchange market, and the U.S. government securities market. An important benefit provided by the $\mathrm{DM}$ is the assurance of immediate execution. An important disadvantage is the cost: the bid-ask spread, which can be substantial. Traders who do not place a high value on immediacy and assured execution can try to reduce their trading costs by searching for counterparties on their own. As computing and communication costs have declined, electronic communication networks have been increasingly deployed to reduce search costs, making it less costly for traders to find one another and reducing the demand for DMs.

* Simon School of Business, University of Rochester, and the Graduate School of Business, Stanford University. Helpful comments and suggestions by an anonymous referee, René Stulz (the editor), and Robert Hendershott are gratefully acknowledged. 
Institutional investors have long recognized the need for alternative markets that provide low-cost execution while sacrificing immediacy and execution guarantees that coexist with the traditional trading institutions. Institutional investors' need for such passive trading mechanisms led to the evolution of crossing networks ${ }^{1}$ (CNs) such as Reuters' Instinet Crossing Network, ITG's POSIT, and the New York Stock Exchange's Crossing Sessions, which are passive call markets that automatically match orders without dealer intervention. The largest of these CNs is POSIT, which has grown over 55 percent a year since 1988 and matched 5.8 billion shares in $1998 .^{2}$ Brokers such as Jack White use the Internet to offer similar services to individual investors, with trades being executed at the midprice between the quoted bid and ask prices. Even though CNs have existed for many years, their growth is a recent phenomenon, and their impact on the coexisting DMs is not well understood.

In this paper, we first examine the operation of a DM and a CN in isolation, and we then focus on the interaction between them. DMs of the type studied here have been analyzed by Garman (1976), Amihud and Mendelson (1980, 1982), Ho and Stoll (1981, 1983), Mildenstein and Schleef (1983), Glosten and Milgrom (1985), Ho and Macris (1985), Grossman and Miller (1988), Madhavan and Smidt (1991, 1993), and Biais (1993). The performance of CNs per se has not been analyzed in the literature, but a related market structure - the "clearing house"-was studied by Mendelson (1982, 1985, 1987). Past theoretical research on multimarket trading used similar market structures to focus on traders' choice of venue (Pagano (1989), Chowdhry and Nanda (1991)) and addresses issues such as the ability of the markets to coexist (Glosten (1994), Parlour and Seppi (1998)). ${ }^{3}$

Our model considers a random number of informed and liquidity traders, each buying or selling one unit of the asset. We study the structure of the equilibria that arise when traders choose between a DM and a CN and derive conditions for the viability of the alternative trading institutions. Dealers' free entry into the market drives the spread down to the competitive level that reflects the dealers' costs. The dealers' spread determines, in part, which traders will choose the DM over the CN. We derive the equilibrium values of the number of dealers, the bid-ask spread, and the number of traders opting for each market. Using this equilibrium, we investigate the impact of the introduction of a $\mathrm{CN}$ on an existing DM and discuss its effects on the spread, the order flows, and social welfare.

\footnotetext{
${ }^{1}$ In its regulations, the SEC (1998, footnote 37$)$ defines a crossing network as a system "that allows participants to enter unpriced orders to buy and sell securities. Orders are crossed at specified times at a price derived from another market."

2 The supranormal Nasdaq spreads noted by Christie and Schultz (1994), Christie, Harris, and Schultz (1994), and others may account for much of POSIT's initial growth, but POSIT's continued growth, for example, 57 percent from 1997 to 1998, must be due to other reasons. Also, POSIT trades primarily listed stock.

${ }^{3}$ A number of papers compare different trading mechanisms in isolation (cf. Mendelson (1987), Madhavan (1992), Biais (1993), Pagano and Röell (1996), Seppi (1997), and Brown and Zhang (1997)).
} 
We find that the relative cost advantage and the volume of trading in the security are key determinants of the competitiveness of a CN. These factors interact with two opposite externalities that prevail on the $\mathrm{CN}$ : on the one hand, the CN is characterized by a positive (or liquidity) externality (Mendelson $(1982,1985)$ ), because an increase in CN trading volume increases its liquidity, benefiting all trades. On the other hand, there is a negative externality, or "crowding" effect: low-liquidity preference trades compete with the higher-liquidity preference trades on the same side of the market. We also identify a critical-mass phenomenon that captures the interaction of declining technology costs and the liquidity externality: once costs are low enough, the $\mathrm{CN}$ will start to attract trading volume, and as more traders use it, it becomes more liquid, attracting additional traders. Once critical mass is reached, however, additional low-liquidity preference trades may not be socially desirable, because these trades compete for execution with the higherliquidity preference trades, crowding them out. This crowding effect can only dominate the liquidity externality after the $\mathrm{CN}$ becomes sufficiently liquid. We also show that accounting for $\mathrm{CN}$ volume is nontrivial. Because not all orders submitted to a $\mathrm{CN}$ execute there, the traditional measure of trading volume underestimates the importance and impact of CNs.

We study how the introduction of a $\mathrm{CN}$ affects both dealers and traders. We demonstrate how traders' choice of the $\mathrm{CN}$ has competing effects on the dealers' order flows, costs, and price efficiency: use of the DM as a "market of last resort" increases its riskiness, but the $\mathrm{CN}$ can reduce adverse selection by attracting new liquidity and providing a venue other than the DM for informed trading. If there is no information asymmetry or the information is short lived and order submission costs are low, the traders' use of the DM as a "market of last resort" always causes dealers to widen their spreads and can lead to more efficient dealer prices. Although this free-riding problem always exists, the CN's low cost can attract new liquidity traders to the market, which can reduce adverse-selection and inventory holding costs and lead to narrower dealer spreads and less efficient prices. This new liquidity can lower dealers' costs by increasing their liquidity-based order flow and, in the case of fundamental, value-based information trading, provide another venue for informed trading. Finally, we show how these outcomes depend on the nature of the insiders' informational advantage, and we study their welfare effects.

The paper proceeds as follows. Section I presents the building blocks of our model. Sections II and III analyze the performance of the DM and CN in isolation. Section IV studies competition between the two trading mechanisms and its implications. Our concluding remarks are offered in Section V.

\section{The Model}

Our model has four building blocks: (i) the traders, (ii) the DM, (iii) the $\mathrm{CN}$, and (iv) competition between the DM and the CN. Each of these is described below. 


\section{A. Traders}

There are two types of traders: informed and liquidity. Each type has a random number of traders willing to buy or sell one unit. The security has a random future value, $\tilde{v}$, that is either $\bar{V}$ or $\underline{V}$ with equal prior probabilities (cf. Easley and O'Hara $(1987,1992)$ ). The realization of $\tilde{v}$ is known to the informed traders. ${ }^{4}$ The security's value has a priori mean $E[\tilde{v}]=(\bar{V}+\underline{V}) / 2$ and volatility $\sigma_{\tilde{v}}=(\bar{V}-\underline{V}) / 2$ per unit. The volatility is equal to the value of the insiders' information, meaning that higher volatility creates more value for the insiders. All insiders are "momentum traders" with probability $\gamma$ or "fundamental traders" with probability $(1-\gamma)$. To benefit from their inside information, momentum traders must trade before the $\mathrm{CN}$ crosses, whereas fundamental traders may wait until after the CN crosses. ${ }^{5}$

For liquidity traders, the value of trading reflects their liquidity preferences, namely, the strength of their desires to buy or sell the security. Liquidity trader $i$ 's liquidity preference for a trade is denoted by $u_{i}$, where the $u_{i} \mathrm{~s}$ are independent and identically distributed (i.i.d.) from a continuous distribution function $F\left(u_{i}\right)$ with non-negative support and $F(u)$ is the probability that a liquidity trader's liquidity preference is greater than $u$.

As in standard liquidity-based market microstructure models, traders' demand for liquidity is conditional on the contemporaneous value of the security (see, e.g., Garman (1976), Cohen et al. (1978, 1981), Amihud and Mendelson (1980), Ho and Stoll (1981), and Mendelson (1982, 1985, 1987)); hence buyer (seller) $i$ 's reservation price is $E[\tilde{v}]+u_{i}\left(E[\tilde{v}]-u_{i}\right)$. We assume that liquidity traders are risk neutral and prefer to trade sooner rather than delay their trades.

The number of informed traders, which we denote by $I_{I}$, is geometrically distributed with expected value $E\left[I_{I}\right]=\lambda_{I}$, that is, $P\left(I_{I}=n\right)=\left(1 /\left(1+\lambda_{I}\right)\right)$ $\cdot\left(\lambda_{I} /\left(1+\lambda_{I}\right)\right)^{n}$ for $n=0,1,2, \ldots{ }^{6}$ Thus, $E\left[I_{I}\right]=\lambda_{I}$, and $\operatorname{Var}\left[I_{I}\right]=\lambda_{I} \cdot\left(1+\lambda_{I}\right)$. Similarly, the number of liquidity-motivated orders on each side of the market is geometrically distributed with expected value $\lambda_{L}{ }^{7}$ We call $\lambda_{L}$ the market "thickness" or "size." The overall order flow is composed of (i) orders on the informed side, $I$, which are geometrically distributed with expected value $\lambda_{I}+\lambda_{L}$ and include both information-motivated and liquidity-motivated trades with respective proportions $\lambda_{I} /\left(\lambda_{L}+\lambda_{I}\right)$ and $\lambda_{L} /\left(\lambda_{L}+\lambda_{I}\right)$; and (ii) orders on the opposite ("liquidity") side, $L$, which are geometrically distributed with expected value $\lambda_{L}$ and are all liquidity motivated.

\footnotetext{
${ }^{4}$ The probabilistic assumptions can be relaxed to yield qualitatively similar results but with greater complexity.

5 This is similar to the overlapping generations model presented in Bernhardt, Hollifield, and Hughson (1995).

${ }^{6}$ An alternative interpretation is that there is one insider trading a random number of units. Under our model, the competing insiders all adopt the same strategy, and the results are equivalent for either interpretation.

7 This is similar to the exponential distribution used in Seppi (1997).
} 


\section{B. Dealer Market (DM)}

Dealers post bid and ask prices at which they will buy or sell, respectively. The dealers receive multiple single-unit orders and cannot distinguish between the informed and liquidity orders. Under this structure, the dealers' bid-ask spread corresponds to each order's market impact (see, e.g., Garman (1976), Amihud and Mendelson (1980), Ho and Stoll (1983), and Glosten and Milgrom (1985)). Because the CN derives its price directly from the dealers' quotes, we focus on the dealers' spread rather than on the individual bid and ask prices. Traders who can only buy from or sell to the dealer pay the half-spread $s(=(A s k-B i d) / 2)$ and have their trades executed with certainty. Dealers bear adverse-selection costs, inventory-holding costs, and opportunity costs for both long and short positions that result from order imbalances. Each dealer's cost is the adverse-selection cost plus the product of a constant $k$ (the dealer's relative risk aversion times the variance of the return on the security) times the expected square of the order imbalance. ${ }^{8}$ That is, when the dealer trades for his own account, he expects to lose money to informed traders, and, additionally, he deviates from his desired portfolio position, assuming risk that he would otherwise avoid and leading to a quadratic cost function. Further, each dealer has a fixed operating cost $A(A>0)$ that includes technology, labor, infrastructure, and opportunity costs. When multiple dealers quote the same price, orders are randomly allocated among them with equal probabilities. Finally, dealers cannot tell which side of the market is likely to have an imbalance or which trades are informed. Following all trading, market participants have better information about the security's value, leading to an expected posterior volatility of $\sigma_{\tilde{v}}^{p} \leq \sigma_{\tilde{v}}$.

We follow the classical industrial organization approach whereby dealers enter the market and compete until spreads just cover their costs. Dealers engage in Bertrand (price) competition, where a dealer (either existing or a new entrant) can capture the entire market by offering customers a better price. If entry and exit are costless, the market will be filled with firms all charging price equal to average cost. ${ }^{9}$

\section{Crossing Network (CN)}

The CN, where traders trade among themselves without the intervention of market makers, provides a pure transactional service with no price discovery. In the examples discussed in the introduction, the security's underlying price can be represented by the midprice between the bid and ask

\footnotetext{
8 This is consistent with dealers having a quadratic utility function with respect to final wealth, where $k$ is proportional to the variance of the security's value. Similar dealer cost or utility functions were used in Stoll (1978), Ho and Stoll (1981, 1983), Mildenstein and Schleef (1983), and Madhavan and Smidt (1991, 1993).

${ }^{9}$ This analysis is predicated on at least two dealers entering and the feasibility of the competitive equilibrium; that is, price equals minimum average cost, supply equals demand, and the quantity corresponds to an integer number of firms operating at their efficient scale.
} 
prices, by the preceding closing price, or by the volume-weighted average price over some period. From a trader's point of view, the cost of trading on the CN consists of two components: $c_{o}$ to submit an order expressing the trader's desire to buy or sell, and $c_{e}$ if that order successfully executes. Typically, $c_{e}$ is charged as a commission needed to cover the CN's costs, whereas $c_{o}$ is the trader's own cost of order submission (e.g., the trader's time and telecommunication cost). ${ }^{10}$

Orders are aggregated and passively matched by the CN. If there is an imbalance, orders on the excess side are randomly selected to match the number of orders on the smaller side. Orders that are not selected do not execute. For example, if there are orders to buy five units and sell three units, all three units are sold and three of the five buy units are randomly selected and executed. Based on the expected quantity of orders going to the $\mathrm{CN}$, each trader can infer the probability that her order will be executed. The decision to submit an order depends on the relationship between this probability and the $\operatorname{costs} c_{o}$ and $c_{e}$ and also on the value the trader places on trading ( $u$ for liquidity traders and $\sigma_{\tilde{v}}$ for the informed trader).

\section{Intermarket Competition}

When both markets coexist, each trader has to decide whether to submit her order to the DM or to the CN. Following common market practice, the two markets are not mutually exclusive: traders can take advantage of both markets by first using the $\mathrm{CN}$ and-if their orders are not executed on the $\mathrm{CN}$-subsequently going to the DM. Traders' decisions are based on their value to trade, the costs in each market, and their estimates of the probability of execution on the CN. Because each trader's decision affects the decisions of all other traders, we model traders' strategies as Nash strategies. That is, each trader chooses her best response given her expectation of all other traders' strategies.

Because the CN aggregates orders and does not operate continuously, traders must wait to have their trades executed on the $\mathrm{CN}$. We assume that a liquidity trader receives a fraction $\delta$ of her value when trading on the CN. That is, the trader's opportunity cost is assumed to be a fraction $(1-\delta)$ of her value, where $0 \leq \delta \leq 1$ is the trader's "impatience factor." 11 If the CN crosses frequently enough or traders are not time sensitive, $\delta=1$, and waiting for the $\mathrm{CN}$ entails no opportunity costs. In this case, all liquidity traders prefer to trade on the CN before trading on the DM (see Section IV.D.2). The informed traders' impatience depends on the nature of their informa-

\footnotetext{
10 The cost parameters $c_{o}$ and $c_{e}$ reflect traders' point of view. From the perspective of the CN's operator, there are both fixed and variable costs. The costs of putting together the software, infrastructure, and network are largely fixed, whereas operating costs such as computing and data-communication costs are mostly variable.

${ }^{11}$ See Amihud, Mendelson, and Lauterbach (1997) for evidence of traders' willingness to pay for immediate execution.
} 
tion: traders with short-lived information (probability $\gamma$ ) trade immediately on their information (as if they had $\delta=0$ ), and fundamental traders with long-lived information (probability $1-\gamma$ ) do not incur a delay cost (as if their $\delta=1$ ).

Each trader decides where to trade based upon her reservation value; the dealer half-spread $s$; the costs of submitting and executing orders on the $\mathrm{CN}$, $c_{o}$ and $c_{e}$; the impatience factor; and the probability of execution on the CN. Traders have four possible strategies: (i) not trading, (ii) trading exclusively on the $\mathrm{CN}$, (iii) trading opportunistically on the $\mathrm{CN}$ : trades that did not execute on the CN move over to the DM, and (iv) trading only in the DM. Each trader chooses the strategy that maximizes her expected net gain given all other traders' strategies. The number of dealers and their bid-ask spreads are determined endogenously, as part of the overall market equilibrium.

In what follows, we analyze the performance of each trading institution in isolation, and we then study the results of competition between the DM and the CN.

\section{Dealer Market (DM)}

We first consider a pure DM that operates without having to compete with the CN. There are no barriers to entry or sunk costs, and identical dealers engage in Bertrand (price) competition: a dealer (either existing or a new entrant) can capture any fraction of the market he desires by offering traders the lowest price.

Traders' decisions are straightforward: they trade in the DM if and only if the cost of trading is less than the value. We focus on the case where the spread is small enough that the informed traders will trade. In equilibrium, each dealer receives the same order flow and quotes the half-spread $s_{D}$ that covers his costs, consisting of losses to the informed trader, the fixed cost $A$, and the risk associated with his final position.

Let $D_{I}$ and $D_{L}$ be the number of orders going to a dealer on the informed and liquidity sides, respectively; and let $J_{D}=D_{I}-D_{L}$ denote his final inventory position. Liquidity traders choose to submit an order only if $u$ is greater than the sum of the half-spread $s_{D}$ and the order cost. We will notationally suppress the fact that the order flow and inventory position are functions of $s_{D_{-}}+c_{o}$. The expected number of orders on the informed side is $E\left[D_{I}\right]=\lambda_{I}+\bar{F}\left(s_{D}+c_{o}\right) \cdot \lambda_{L}$, and the expected number of orders on the liquidity side is $E\left[D_{L}\right]=\bar{F}\left(s_{D}+c_{o}\right) \cdot \lambda_{L}$. The expected value of the squared order imbalance is

$$
\begin{aligned}
E\left[{J_{D}}^{2}\right]= & E\left[D_{I}+D_{L}\right]+2\left(E\left[D_{I}\right]^{2}-E\left[D_{I}\right] \cdot E\left[D_{L}\right]+E\left[D_{L}\right]^{2}\right) \\
= & \lambda_{I}+2 \cdot \bar{F}\left(s_{D}+c_{o}\right) \cdot \lambda_{L}+2\left(\lambda_{I}^{2}+\lambda_{I} \cdot \bar{F}\left(s_{D}+c_{o}\right) \cdot \lambda_{L}\right. \\
& \left.+\left(\bar{F}\left(s_{D}+c_{o}\right) \cdot \lambda_{L}\right)^{2}\right) .
\end{aligned}
$$


By symmetry, each dealer's expected number of informed-side orders is $E\left[D_{I, i}\right]=E\left[D_{I}\right] / n=\left[\lambda_{I}+\bar{F}\left(s_{D}+c_{o}\right) \cdot \lambda_{L}\right] / n$, and his expected number of liquidity-side orders is $E\left[D_{L, i}\right]=E\left[D_{L}\right] / n=\left[\bar{F}\left(s_{D}+c_{o}\right) \cdot \lambda_{L}\right] / n$. Substituting $D_{I, i}$ and $D_{L, i}$ into equation (1), the expected squared value of dealer $i$ 's inventory is

$$
\begin{aligned}
E\left[J_{D, i}^{2}\right]= & E\left[D_{I, i}+D_{L, i}\right]+2\left(E\left[D_{I, i}\right]^{2}-E\left[D_{I, i}\right] \cdot E\left[D_{L, i}\right]+E\left[D_{L, i}\right]^{2}\right) \\
= & \frac{\lambda_{I}+2 \cdot \bar{F}\left(s_{D}+c_{o}\right) \cdot \lambda_{L}}{n} \\
& +2\left(\frac{\lambda_{I}{ }^{2}+\bar{F}\left(s_{D}+c_{o}\right) \cdot \lambda_{L} \cdot \lambda_{I}+\left(\bar{F}\left(s_{D}+c_{o}\right) \cdot \lambda_{L}\right)^{2}}{n^{2}}\right),
\end{aligned}
$$

which shows that a dealer's expected inventory risk is a positive quadratic form in the expected order flows. This implies that splitting the order flow between two dealers reduces the total inventory risk. Hence, adding dealers reduces the inventory risk-but increases total fixed costs. This trade-off between fixed costs and inventory risk leads to a U-shaped cost function that allows multiple dealers to engage in Bertrand competition and still coexist.

If $n$ dealers quote the same half-spread, $s_{D}$, each dealer's profit function is given by

$$
\begin{aligned}
\pi(n)= & s_{D} \cdot E\left[D_{I, i}+D_{L, i}\right]-A-\sigma_{\tilde{v}} \cdot E\left[D_{I, i}-D_{L, i}\right]-k \cdot E\left[J_{D, i}{ }^{2}\right] \\
= & s_{D} \cdot E\left[D_{I, i}+D_{L, i}\right]-A-\sigma_{\tilde{v}} \cdot E\left[D_{I, i}-D_{L, i}\right] \\
& -k\left(E\left[D_{I, i}+D_{L, i}\right]+2\left(E\left[D_{I, i}\right]^{2}-E\left[D_{I, i}\right] \cdot E\left[D_{L, i}\right]+E\left[D_{L, i}\right]^{2}\right)\right) .
\end{aligned}
$$

Without barriers to entry or sunk costs, dealers will continue to enter until all quote the half-spread that just covers their costs. Under these conditions, the competitive equilibrium - the equilibrium number of dealers, their spreads, and their order flows-can be found by setting equation (3) equal to zero with the efficient (total-cost minimizing) number of dealers, as given by the following proposition. ${ }^{12}$

Proposition 1: The unique Nash Equilibrium is for

$$
n=\sqrt{\frac{k}{A}} \cdot \sqrt{E\left[J_{D}^{2}\right]-E\left[D_{I}+D_{L}\right]}
$$

${ }^{12}$ All proofs are in the Appendix. 
dealers to trade expected quantity $q=E\left[D_{I}+D_{L}\right] / n$ by quoting the identical half-spread given by the smallest root of

$$
s_{D}=\sigma_{\tilde{v}} \cdot \frac{E\left[D_{I}-D_{L}\right]}{E\left[D_{I}+D_{L}\right]}+k+\frac{2 \cdot A}{q} .
$$

The number of dealers given by equations (4) and (5) is increasing in the dealers' risk aversion $k$ and the expected amount of liquidity trading, $\lambda_{L}$, and decreasing in the fixed cost, $A$. Interestingly, the number of dealers can be either increasing or decreasing in the amount of informed trading, $\lambda_{I}$. Increasing the informed quantity increases the right-hand side of equation (4) but also increases the dealers' half-spread, $s_{D}$, which reduces the number of liquidity traders, in turn reducing the number of dealers. The latter effect is stronger if $\lambda_{L}$ is large relative to $\lambda_{I}$.

The first term in the equilibrium half-spread in equation (5) is the adverse selection component of the spread, given by the expected losses to the insiders divided by the total quantity of orders. The second term in equation (5) is the linear inventory risk term. At the dealers' efficient scale, the amortized fixed cost is equal to the quadratic part of the inventory risk; hence the final term in equation (5), which represents the quadratic inventory risks and the amortized fixed cost, is twice the amortized fixed cost. There may be multiple solutions to equation (5), but only the smallest solution is consistent with free entry into the DM.

Additional liquidity trading reduces both the adverse selection and the fixed and quadratic inventory components of the spread. If fewer liquidity traders use the DM, the spread will widen, causing even fewer liquidity traders to use the DM. However, if the amount of informed trading in the $\mathrm{DM}$ is reduced, the spread narrows, attracting additional liquidity trades and leading to an even narrower spread. These effects become important when we allow traders to choose between the DM and the CN. Also, just as the CN can have difficulty achieving critical mass, if the dealers' spread is large enough, the DM may not attract any liquidity trading, resulting in market failure.

After observing the net trading by the dealers, market participants can make an inference regarding which side of the market the informed traders were on, reducing the expected posterior volatility of the security's value, $\sigma_{\tilde{v}}^{p}$. The greater the order imbalance in the DM, the more learning occurs and the lower the subsequent volatility of the security's value. Lower value volatility allows dealers to narrow their spreads and increase price efficiency. When more informed orders flow to the DM, post-trading value volatility decreases and price efficiency increases. Additional informed trading reduces the posterior value volatility in two ways: the post-trading value volatility conditional on the order imbalance falls, and the order imbalance volatility increases. More liquidity trading increases the posterior value volatility conditional on the order imbalance and increases the order imbalance volatility. 
The bid-ask spread is an increasing function of the dealers' fixed cost $A$. Assuming that these costs have declined over time, bid-ask spreads would tend to decrease over time. However, because the time trends for the other model parameters are not empirically clear, this model cannot produce sharp predictions regarding the behavior of bid-ask spreads over time.

Dealers profit via the spread on those trades for which they can find a counterparty, but they lose money on their final positions through adverse selection and the risk associated with the position. On average, dealers' trading revenues balance out the cost of their final positions. They break even by amortizing the losses from the unbalanced trades over the balanced trades. Any changes in the composition of the dealers' order flow can affect both the number of dealers and their spread.

The equilibrium in Proposition 1 allows dealers to implicitly share their inventory risks by sharing the order flow. If, after trading with the public, dealers trade among themselves until all of their positions are equalized, their risk can be further reduced (cf. Reiss and Werner (1998)). Such explicit risk sharing can be modeled as dealers equally sharing the overall residual inventory. Letting $J_{D,(i)}$ denote dealer $i$ 's inventory under such risk sharing, we can rewrite equation (2) as

$$
E\left[J_{D,(i)}^{2}\right]=E\left[{J_{D, i}}^{2}\right]-\left(\frac{n-1}{n^{2}}\right) E\left[D_{I}+D_{L}\right] .
$$

Clearly, risk sharing by dealers who trade to eliminate offsetting positions reduces their inventory risk. Equation (6) shows that the risk specific to a particular dealer can be eliminated by interdealer trading. The impact of risk sharing on DM equilibrium is given by the following proposition.

Proposition 2: Under explicit dealer risk sharing, the unique Nash Equilibrium is for

$$
n=\sqrt{\frac{k}{A}} \cdot \sqrt{E\left[J_{D}^{2}\right]+E\left[D_{I}+D_{L}\right]}
$$

dealers to trade expected quantity $q=E\left[D_{I}+D_{L}\right] / n$ by quoting the halfspread given by the smallest root of

$$
s_{D}=\sigma_{\tilde{v}} \cdot \frac{E\left[D_{I}-D_{L}\right]}{E\left[D_{I}+D_{L}\right]}+\frac{2 \cdot A}{q} .
$$

Dealer risk sharing increases the number of dealers, narrows the bid-ask spread, and achieves the first best equilibrium.

Because the socially optimal number of dealers participates under free entry and dealers minimize their costs by sharing the risk efficiently, the first best outcome can be achieved through the interdealer trading suggested by Reiss and Werner. 


\section{Performance Analysis: CN}

We examine first the case of no informed trading $\left(\lambda_{I}=0, \lambda_{L}=\lambda\right)$ and then extend the analysis to include informed trading. When only the $\mathrm{CN}$ is available, traders have to decide whether or not to submit orders for trading on it. A trader will choose not to submit an order if her expected gains from trade are less than the cost of order submission. Thus, only a fraction, say, $\alpha$, of traders may actually submit orders to the CN. ${ }^{13}$ The resulting distribution of the number of trades is given by the following lemma, whose proof is straightforward.

Lemma 1: If fraction $\alpha$ of potential traders join the $C N$, the distribution of the number of buy (sell) orders in the $C N$ is geometric with mean $\alpha \cdot \lambda$.

Defining $C_{b}(\alpha)$ and $C_{s}(\alpha)$ to be the number of buy and sell orders in the $\mathrm{CN}$, we have

$$
\begin{aligned}
E\left[C_{b}(\alpha)\right] & =\alpha \cdot \lambda, \\
E\left[\left(C_{b}(\alpha)-C_{s}(\alpha)\right)^{2}\right] & =\operatorname{Var}\left[C_{b}(\alpha)\right]+\operatorname{Var}\left[C_{s}(\alpha)\right] \\
& =2 \cdot \alpha \cdot \lambda \cdot(1+\alpha \cdot \lambda), \\
E\left[\left|C_{b}(\alpha)-C_{s}(\alpha)\right|\right] & =2 \cdot \alpha \cdot \lambda \cdot \frac{1+\alpha \lambda}{1+2 \alpha \lambda},
\end{aligned}
$$

and the number of actual trades that takes place, $C_{T}(\alpha)=\min \left(C_{b}(\alpha), C_{s}(\alpha)\right)$, is geometrically distributed with parameter $E\left[C_{T}(\alpha)\right]=\frac{(\alpha \lambda)^{2}}{1+2 \alpha \lambda} .{ }^{14}$

In deciding whether to submit an order to the $\mathrm{CN}$, each trader has to evaluate her probability of execution, given by the following proposition.

Proposition 3: If the number of buyers and sellers is geometrically distributed with parameter $\alpha \cdot \lambda$, then the probability that a buyer (seller) receives an execution in the $C N$ is

$$
\log \left(1+\frac{\alpha \cdot \lambda}{1+\alpha \cdot \lambda}\right)
$$

The probability of execution is a concave and increasing function of the market size, $\lambda$. The larger the average number of traders in the market, the higher the probability of execution. However, that probability is always bounded

${ }^{13}$ With the CN competing with a DM, some traders may opt for the DM, further reducing $\alpha$. See Section IV.B.

${ }^{14}$ The minimum of two geometric random variables with parameter $q$, where $q$ is the probability of a success, is geometrically distributed with parameter $q^{2}$. Under our formulation, $q=$ $\frac{\alpha \lambda}{1+\alpha \lambda}$; hence the expected number of trades is $\frac{\left(\frac{\alpha \lambda}{1+\alpha \lambda}\right)^{2}}{1-\left(\frac{\alpha \lambda}{1+\alpha \lambda}\right)^{2}}=\frac{(\alpha \lambda)^{2}}{1+2 \alpha \lambda}$. 
by $\log 2$, which is less than unity. This means that traders can never be guaranteed an execution on the CN, no matter how "thick" the market is. The rate at which the probability of execution increases with the addition of traders is large for very small markets but quickly diminishes, reaching 88 percent of its maximum with only five expected traders on each side of the market. The increase in the probability of execution as more traders go to the $\mathrm{CN}$ is a reflection of a positive liquidity externality (Mendelson (1982, 1985)): as the expected number of traders increases, each is more likely to find a match on the other side, raising the probability of execution for all traders. Hence, the larger the market, the easier it is to find an executionthe more "liquid" it is.

For CNs, the liquidity externality is well understood in practice. CNs have been closed when they failed to attract enough volume (e.g., the Chicago Match operated by the Chicago Stock Exchange), and CNs sometimes share volume to improve the performance of each. A recent example is an agreement allowing Jack White to transfer its orders to POSIT, which increases the probability of execution in both CNs.

\section{A. Equilibria}

Because of traders' order submission and execution costs, even absent competition from a DM only a fraction $\alpha$ of traders will choose to trade on the CN. We next determine that fraction.

Given a trader's realized value, $u$, her expected net benefit from trading is $\delta \cdot u-c_{e}$ times the probability of execution, which is $\log \left(1+\frac{\alpha \lambda}{1+\alpha \lambda}\right)$. Her expected net gain is the difference between her expected net benefit and her order cost, $c_{o}$. All traders with nonnegative expected net gains will use the $\mathrm{CN}$ in equilibrium. Because these gains increase in value, if a trader with value $u$ chooses to use the $\mathrm{CN}$, so will all traders with values greater than $u$. Thus, an equilibrium is characterized by a cutoff value, $\hat{u}$, such that traders with $u>\hat{u}$ use the CN, those with values below $\hat{u}$ do not, and traders with value $\hat{u}$ are indifferent.

Because a fraction $\alpha=\bar{F}(\hat{u})$ of traders submit orders, by Proposition 3 the probability that any trader receives an execution is $\log \left(1+\frac{\bar{F}(\hat{u}) \lambda}{1+\bar{F}(\hat{u}) \lambda}\right)$, and the expected net gain for a trader with value $u$ is given by

$$
g(u, \hat{u})=\left(\delta \cdot u-c_{e}\right) \cdot \log \left(1+\frac{\bar{F}(\hat{u}) \lambda}{1+\bar{F}(\hat{u}) \lambda}\right)
$$

Clearly, $g(u, 0)=-c_{e} \cdot \log \left(1+\frac{\lambda}{1+\lambda}\right), g\left(\frac{c_{e}}{\delta}, \hat{u}\right)=0$, and $\lim _{\hat{u} \rightarrow \infty} g(u, \hat{u})=0$ (when $u=\hat{u}$, we suppress the first argument of $g(u, \hat{u})$ and use $g(\hat{u}))$. By continuity, the cutoff value $\hat{u}$ must satisfy

$$
g(\hat{u})=c_{o}
$$




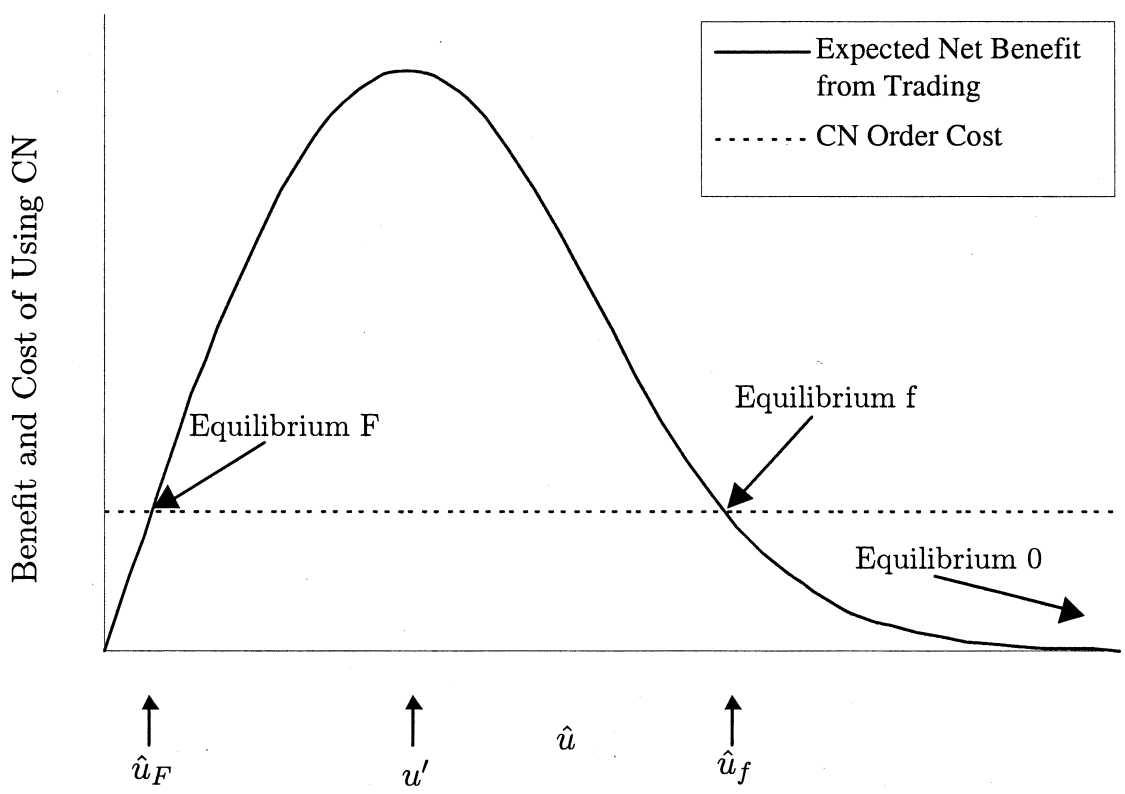

Figure 1. Equilibria-CN only. CN order cost and the net benefit from trading for the marginal trader-a trader with the equilibrium cutoff liquidity value, $\hat{u}$-are plotted as a function of the possible equilibrium cutoff values.

The properties of the function $g$ affect the number of solutions to equation (12). We assume that the function $g(\hat{u})$ is unimodal, ${ }^{15}$ that is, there exists a $u^{\prime}$ such that $g(u)$ is increasing for $u<u^{\prime}$ and decreasing for $u>u^{\prime}$. Under this assumption, equation (12) has at most two solutions, each corresponding to a possible equilibrium. We call these solutions equilibrium $\mathrm{f}$ (the smaller solution to equation (12) where $\hat{u}=\hat{u}_{f}$ and a smaller fraction of traders use the $\mathrm{CN}$ ) and equilibrium $\mathrm{F}$ (the larger solution where $\left.\hat{u}=\hat{u}_{F}\right)$. If $g(\hat{u})$ is always less than $c_{o}$, equation (12) has no solution, and the CN fails to achieve critical mass, that is, it cannot attract any orders.

The existence of multiple equilibria is consistent with previous work (e.g., Katz and Shapiro (1985)) showing that in markets with positive externalities, traders' beliefs are important in determining the equilibrium. In addition, the dependence on traders' beliefs introduces a third equilibrium, which we call equilibrium 0: if the highest-value traders do not believe that any other traders will use the CN, then nobody uses the CN. This corresponds to $\hat{u}=\hat{u}_{0}=\infty$, where the probability of execution on the $\mathrm{CN}$ is zero and hence no trader wants to join it. Figure 1 illustrates the possible equilibria, show-

15 This assumption is met for reasonable parameter values for distributions with density functions that have their mode at zero and decrease thereafter, such as the exponential and truncated normal. 
ing the expected net benefit from trading on the CN, $g(u, \hat{u})$, and the cost of submitting an order to the $\mathrm{CN}, c_{o}$, for each value $u$ when that same value is the cutoff value $(u=\hat{u}) .{ }^{16}$

By Proposition 3, increasing the number of orders in the $\mathrm{CN}$ increases the probability of execution. If enough traders use the $\mathrm{CN}$, this probability rises to the point where the expected benefits cover the order submission $\operatorname{cost} c_{o}$ and the $\mathrm{CN}$ achieves critical mass. In Figure 1, this first occurs in equilibrium $\mathrm{f}$, where $\hat{u}=\hat{u}_{f}$. At this point, an entire group of traders joins the $\mathrm{CN}$, whereas for equilibrium $0(\hat{u}=\infty)$, no trader wants to use the CN. Because the benefit curve is above $c_{o}$ for cutoff values less than $\hat{u}_{f}$ and below $c_{o}$ for values greater than $\hat{u}_{f}$, equilibrium $\mathrm{f}$ is not stable. ${ }^{17}$

The other point where the cost and benefit curves cross is equilibrium $F$ where $\hat{u}=\hat{u}_{F}$. Because the benefits of using the CN are greater than the costs for values between $\hat{u}_{F}$ and $\hat{u}_{f}$, all traders prefer equilibrium $\mathrm{F}$ to equilibrium $f$, but because the costs and benefits are equal at $\hat{u}_{f}$, no trader with value less than $\hat{u}_{f}$ is willing to unilaterally go to the $\mathrm{CN}$.

The above analysis is formally summarized by the following proposition.

Proposition 4: If the function $g(\hat{u})$ is unimodal, there are at most three possible equilibria:

equilibrium $0 \quad$ where no traders use the $C N(\hat{u}=\infty)$;

equilibrium $f \quad$ where a small fraction of traders use the $C N\left(\hat{u}=\hat{u}_{f}\right)$; and

equilibrium $F \quad$ where a large fraction of traders use the $C N\left(\hat{u}=\hat{u}_{F}\right)$;

where $\hat{u}_{f}$ and $\hat{u}_{F}$ correspond to the smaller and larger root of the equation $g(\hat{u})=c_{o}$.

The order and execution costs have different effects on the equilibria, because $c_{o}$ is always incurred, whereas $c_{e}$ is paid only upon successful execution. Equilibrium $f$ exists because of cost to attempt to trade, but the expected benefit depends on all other traders' actions. If $c_{o}=0$, equilibrium $\mathrm{f}$ disappears and either all traders with value above $\frac{c_{e}}{\delta}$ trade on the $\mathrm{CN}$ (equilibrium F) or no traders use the $\mathrm{CN}$ (equilibrium 0).

Increasing the transaction costs, either $c_{o}$ or $c_{e}$, increases the cutoff value $\hat{u}$ for equilibria $f$ and $F$, reducing the number of traders who choose to trade on the CN. This process feeds on itself: as the number of traders declines, so does the probability of execution, which makes the CN less attractive, further reducing its liquidity. Thus, as seen in Figure 1, a critical mass of traders is needed for even the highest-value traders to consider the CN.

\footnotetext{
${ }^{16}$ In essence, Figure 1 tests each value of $u$ to see whether it satisfies the equilibrium conditions.

${ }^{17} \mathrm{By}$ this we mean that if any of the traders with values greater than $\hat{u}_{f}$ did not trade on the $\mathrm{CN}$, then all traders would cease to use the CN (equilibrium 0). If any of the traders with values less than $\hat{u}_{f}$ did trade on the CN, additional traders would join until $\hat{u}=\hat{u}_{F}$ (equilibrium F). When $\lambda \rightarrow \infty$, equilibria 0 and $\mathrm{f}$ converge to a single unstable equilibrium.
} 
To find this critical mass, let $u^{\prime}$ be the value of $\hat{u}$ that maximizes $g(\hat{u})$, namely, $u^{\prime}$ is the solution to $\delta \cdot \log \left(1+\frac{\bar{F}(\hat{u}) \lambda}{1+\bar{F}(\hat{u}) \lambda}\right)=\frac{\left(\delta \hat{u}-c_{e}\right) F^{\prime}(\hat{u}) \lambda}{(1+\bar{F}(\hat{u}) \lambda)(1+2 \bar{F}(\hat{u}) \lambda)}$. If $g\left(u^{\prime}\right)<c_{o}$, then critical mass can never be reached and no trader will trade on the CN. ${ }^{18}$ In "thicker" markets (higher $\lambda$ ), critical mass is more easily achieved. This is also true when traders are less time sensitive (i.e., $\delta$ is higher) or the costs of using the $\mathrm{CN}\left(c_{e}\right.$ or $\left.c_{o}\right)$ are lower. In addition, if traders have a stronger liquidity preference, the market becomes more liquid. Formally, if $F_{1}(u)$ stochastically dominates $F(u), F_{1}(u)<F(u)$ for all $u$, then the equilibrium value of $\hat{u}$ under $F_{1}(u)$ is lower than under $F(u)$, and critical mass is more easily reached under $F_{1}(u)$.

In practice, the primary determinants of $c_{o}$ are computing and telecommunications costs. As $c_{o}$ falls, the $\mathrm{CN}$ becomes more attractive, and $\mathrm{CNs}$ become viable for smaller markets. These results are consistent with the relatively recent growth in the use of $\mathrm{CNs}$ and the move toward making $\mathrm{CNs}$ available to retail customers.

\section{B. CN with Informed Trading}

We next extend our analysis to the case where some of the order flow comes from informed traders (as described in Section I.A). If the informed traders decide not to trade on the CN, the equilibria in Section III.A apply. Hence, we assume that the informed traders choose to trade on the CN (i.e., the information is sufficiently valuable). Their trading affects the liquidity traders' choices both through the probability of execution and via possible adverse selection costs. We first derive the effect on the probability of execution.

\section{B.1. Probability of Execution with an Informed Trader}

The effect of informed trading on liquidity traders depends on whether they are on the same side of the market (event $I_{1}$ ) or on opposite sides (event $\left.I_{0}\right)$. With the expected number of liquidity buyers and sellers being $\bar{F}(\hat{u}) \cdot \lambda_{L}$ and the expected number of informed quantity being $\lambda_{I}$, the probability that a liquidity buyer (seller) receives an execution on the CN when the informed traders are buying (selling) is

$$
P\left(\operatorname{trade} \mid I_{1}, \hat{u}\right)=\frac{\bar{F}(\hat{u}) \cdot \lambda_{L}}{\lambda_{I}+\bar{F}(\hat{u}) \cdot \lambda_{L}} \log \left(1+\frac{\lambda_{I}+\bar{F}(\hat{u}) \cdot \lambda_{L}}{\bar{F}(\hat{u}) \cdot \lambda_{L}+1}\right) .
$$

If the informed traders are selling (buying), the probability that a liquidity buyer (seller) receives an execution in the $\mathrm{CN}$ is

$$
P\left(\operatorname{trade} \mid I_{0}, \hat{u}\right)=\frac{\lambda_{I}+\bar{F}(\hat{u}) \cdot \lambda_{L}}{\bar{F}(\hat{u}) \cdot \lambda_{L}} \log \left(1+\frac{\bar{F}(\hat{u}) \cdot \lambda_{L}}{\lambda_{I}+\bar{F}(\hat{u}) \cdot \lambda_{L}+1}\right)
$$

${ }^{18}$ When $g\left(u^{\prime}\right)=c_{o}$, equilibria $\mathrm{f}$ and $\mathrm{F}$ are identical and unstable. 
Clearly, the liquidity trader is more likely to trade when the informed traders are on the other side of the market, $P\left(\operatorname{trade} \mid I_{0}\right) \geq P\left(\operatorname{trade} \mid I_{1}\right)$. This adverse selection may reduce the attractiveness of trading on the $\mathrm{CN}$. To calculate the unconditional probability of execution, liquidity traders equally weigh the two possibilities, namely, $P($ trade $\mid \hat{u})=P\left(\right.$ trade $\left.\mid I_{0}, \hat{u}\right)+P\left(\right.$ trade $\left.\mid I_{1}, \hat{u}\right) / 2$. Holding $\hat{u}$ constant and comparing to equation (10), we note that the informed traders may increase or decrease a liquidity trader's probability of execution on the $\mathrm{CN}$. When $\lambda_{I}$ is low, the informed traders enable more traders on the other side of the market to trade without providing too much competition for the liquidity trades on the same side. But as $\lambda_{I}$ grows, the CN becomes unbalanced, and $P($ trade $\mid \hat{u})$ approaches $1 / 2$, which is less than the probability of execution without an informed trader when $\bar{F}(\hat{u}) \cdot \lambda_{L}>$ $[1 /(2-\sqrt{e})]-1$.

\section{B.2. CN Equilibria with an Informed Trader}

Using Bayes' rule, liquidity traders can determine their expected adverseselection cost, that is, the difference between the security's prior expected value, $E[\tilde{v}]$, and its expected value conditional on trading,

$$
\begin{gathered}
E[\tilde{v} \mid \text { selling, } \hat{u}]-E[\tilde{v}]=E[\tilde{v}]-E[\tilde{v} \mid \text { buying, } \hat{u}] \\
=\sigma_{\tilde{v}}\left(\frac{P\left(\operatorname{trade} \mid I_{0}, \hat{u}\right)-P\left(\operatorname{trade} \mid I_{1}, \hat{u}\right)}{P(\operatorname{trade} \mid \hat{u})}\right) .
\end{gathered}
$$

Similar to equation (12), the equilibrium equation for $\hat{u}$ with insider trading is

$$
\begin{aligned}
g_{I}(\hat{u}) & =\left(E[\tilde{v}]+\delta \cdot \hat{u}-E[\tilde{v} \mid \text { selling }, \hat{u}]-c_{e}\right) P(\text { trade } \mid \hat{u}) \\
& =\left(\delta \cdot \hat{u}-c_{e}\right) P(\operatorname{trade} \mid \hat{u})-\sigma_{\tilde{v}}\left(P\left(\text { trade } \mid I_{0}, \hat{u}\right)-P\left(\text { trade } \mid I_{1}, \hat{u}\right)\right)=c_{o} .
\end{aligned}
$$

The equilibria have the same form as those of Proposition 4. Furthermore, $g(\hat{u})-g_{I}(\hat{u})=\sigma_{\tilde{v}}\left(P\left(\right.\right.$ trade $\left.\mid I_{0}, \hat{u}\right)-P\left(\right.$ trade $\left.\left.\mid I_{1}, \hat{u}\right)\right)$, implying that $\hat{u}$ is smaller with the informed trader: clearly, liquidity traders find a market with adverse selection less attractive, making it more difficult for the $\mathrm{CN}$ to achieve critical mass. Indeed, to prevent the adverse selection from reducing participation and the probability of execution, some $\mathrm{CNs}$ attempt to limit participation to institutions that manage "passive" portfolios. ${ }^{19}$ By equation (15), $\left[\partial\left(P\left(\right.\right.\right.$ trade $\left.\mid I_{0}, \hat{u}\right)-P\left(\right.$ trade $\left.\left.\left.\mid I_{1}, \hat{u}\right)\right)\right] / \partial \hat{u}>0$ : increasing the expected number of liquidity traders reduces the probability that each loses by trading against the informed. This happens because the total adverse-selection cost is shared by the liquidity traders, similar to Admati and Pfleiderer's (1988) finding that liquidity traders all want to trade together.

\footnotetext{
${ }^{19}$ As shown in Section IV.C, this is sometimes undesirable.
} 
The above discussion of liquidity traders' adverse-selection costs applies when their probability of execution depends on the insiders' trading. If the liquidity traders have the option of trading in a DM (Section II), they can eliminate their adverse-selection costs by going to the DM. The dealers then bear the adverse-selection costs, which are incorporated into their spread.

\section{Externalities on the $C N$}

The above results show that increasing the order flow of liquidity traders makes the CN more attractive to liquidity traders for two different reasons: (i) it increases the probability of execution, and (ii) it reduces their expected adverse-selection cost. However, increasing the liquidity-motivated order flow also inflicts a negative externality on traders on the same side of the market through crowding. Thus, the operation of the CN is characterized by both positive and negative externalities. As we illustrate below, which externalities are stronger depends on how liquid the market is.

As is commonly done in models of asymmetric information, we focus on the welfare of liquidity traders. To evaluate their total surplus, we calculate their gains from trade and their implicit and explicit costs. The expected quantity traded on the $\mathrm{CN}$ is $E\left[C_{T}(\hat{u})\right]=\left[\bar{F}(\hat{u}) \lambda_{L}\left(\lambda_{I}+\bar{F}(\hat{u}) \lambda_{L}\right)\right] /\left[2 \bar{F}(\hat{u}) \lambda_{L}+\right.$ $\left.\lambda_{I}+1\right]$, with $E\left[C_{T, L}(\hat{u})\right]=\left[\bar{F}(\hat{u}) \lambda_{L}\left(\lambda_{I}+2 \bar{F}(\hat{u}) \lambda_{L}\right)\right] /\left[2 \bar{F}(\hat{u}) \lambda_{L}+\lambda_{I}+1\right]$ liquidity orders being executed and $E\left[C_{T, I}(\hat{u})\right]=\bar{F}(\hat{u}) \lambda_{L} \lambda_{I} /\left[2 \bar{F}(\hat{u}) \lambda_{L}+\lambda_{I}+1\right]$ informed units trading. The expected net gains of liquidity traders are equal to their expected gross gains, minus adverse-selection cost (= insiders' gross gain), minus the execution cost for each execution, minus the order cost for each order submitted. This gives rise to the following proposition.

Proposition 5: For a given cutoff value $\hat{u}$, the surplus generated by the $C N$ for liquidity traders is

$$
T S(\hat{u})=E\left[C_{T, L}(\hat{u})\right] \cdot\left(\delta \cdot E[u \mid u \geq \hat{u}]-c_{e}\right)-E\left[C_{T, I}(\hat{u})\right] \cdot \sigma_{\tilde{v}}-2 \cdot \bar{F}(\hat{u}) \cdot \lambda_{L} \cdot c_{o} .
$$

For the traders as a group, reducing the number of liquidity traders by increasing $\hat{u}$ has two opposite effects: the number of orders executed decreases, but the expected surplus per trade increases. The net effect of increasing $\hat{u}$ on liquidity traders' surplus is given by

$$
\begin{aligned}
\frac{\partial T S(\hat{u})}{\partial \hat{u}}= & \frac{\partial E\left[C_{T, L}(\hat{u})\right]}{\partial \hat{u}}\left(\delta \cdot E[u \mid u \geq \hat{u}]-c_{e}\right)+\delta \cdot E\left[C_{T, L}(\hat{u})\right] \cdot \frac{\partial E[u \mid u \geq \hat{u}]}{\partial \hat{u}} \\
& -\frac{\partial E\left[C_{T, I}(\hat{u})\right]}{\partial \hat{u}} \cdot \sigma_{\tilde{v}}+2 \cdot \lambda_{L} \cdot c_{o} \cdot F^{\prime}(\hat{u}) .
\end{aligned}
$$

The first term in equation (17) represents the effect of fewer executions; the second reflects the restriction to higher-quality executions, the third the reduction in losses to the informed trader, and the fourth the reduction 
in order costs. Because the first term of equation (17) is negative and the rest are positive, equation (17) is not uniquely signed. Thus, excluding some liquidity traders can increase surplus. This effect is seen most readily as $\lambda_{L} \rightarrow \infty$, where the expected surplus per liquidity trader is given by

$$
\lim _{\lambda_{L} \rightarrow \infty} \frac{T S(\hat{u})}{\lambda_{L}}=\left(\delta \cdot E[u \mid u \geq \hat{u}]-c_{e}\right) \bar{F}(\hat{u})-2 \cdot \bar{F}(\hat{u}) \cdot c_{o} .
$$

The derivative of equation (18) is $F^{\prime}(\hat{u})\left(2 \cdot c_{o}+c_{e}-\delta \cdot \hat{u}\right)$, which is maximized at $\hat{u}+\left(2 c_{o}+c_{e}\right) / \delta$. By equation (12), the equilibrium cutoff in a "thick" market is $\left[\left(c_{o} / \log 2\right)+c_{e}\right] / \delta$ which (for $\left.c_{o}>0\right)$ is less than the socially optimal cutoff: $\left(2 c_{o}+c_{e}\right) / \delta=\left[\left(c_{o} / \log 2\right)+c_{e}\right] / \delta .{ }^{20}$ This means that in equilibrium, more traders will go to the $\mathrm{CN}$ than is socially desirable, which is why we refer to this phenomenon as "crowding."

The reason the $\mathrm{CN}$ becomes crowded is that, as shown in Proposition 6 below, the probability of execution as evaluated by an individual trader cannot be properly used to calculate the aggregate amount of trading. This discrepancy between the individual and market calculus results in a negative externality because the aggregation of the individually calculated probabilities leads to more traders joining the $\mathrm{CN}$ than is desirable from an overall welfare perspective.

PRoposition 6: The expected number of liquidity orders executed on the $C N$ is less than the expected number of liquidity orders submitted to the CN times the expected probability that each liquidity order will execute.

The effect of Proposition 6 is evident in comparing the way a liquidity trader calculates her probability of execution to the $\mathrm{CN}$-wide calculation of the expected number of liquidity trades. The probability that a given buy order is executed conditional on the total number of buyers is decreasing in the total number of buyers. Hence, the expected number of buyers that trade is less than the expected number of buyers times the probability, calculated by a buyer, that her order will be executed (the analysis for sellers is identical):

$E\left[N_{b} \cdot P\left\{\right.\right.$ buyer gets an execution $\left.\left.\mid N_{b}\right\}\right]<E\left[N_{b}\right] \cdot P\{$ buyer gets an execution $\}$.

Thus, each individual liquidity trader does not have enough information about the number of other liquidity traders to accurately extend her subjectively evaluated execution probability to the entire market. This discrepancy causes low-liquidity preference traders to join the $\mathrm{CN}$ even though they do not have a positive contribution to overall surplus. In the likely case of an imbalance,

\footnotetext{
${ }^{20}$ With the CN only, no "crowding" occurs in a thick market when $c_{o}=0$, because traders need not factor the probability of execution into their decisions. As shown in Section IV.D.2, when traders choose between the DM and the CN, they must take the probability of execution into account, and "crowding" occurs when $c_{o}=0$.
} 


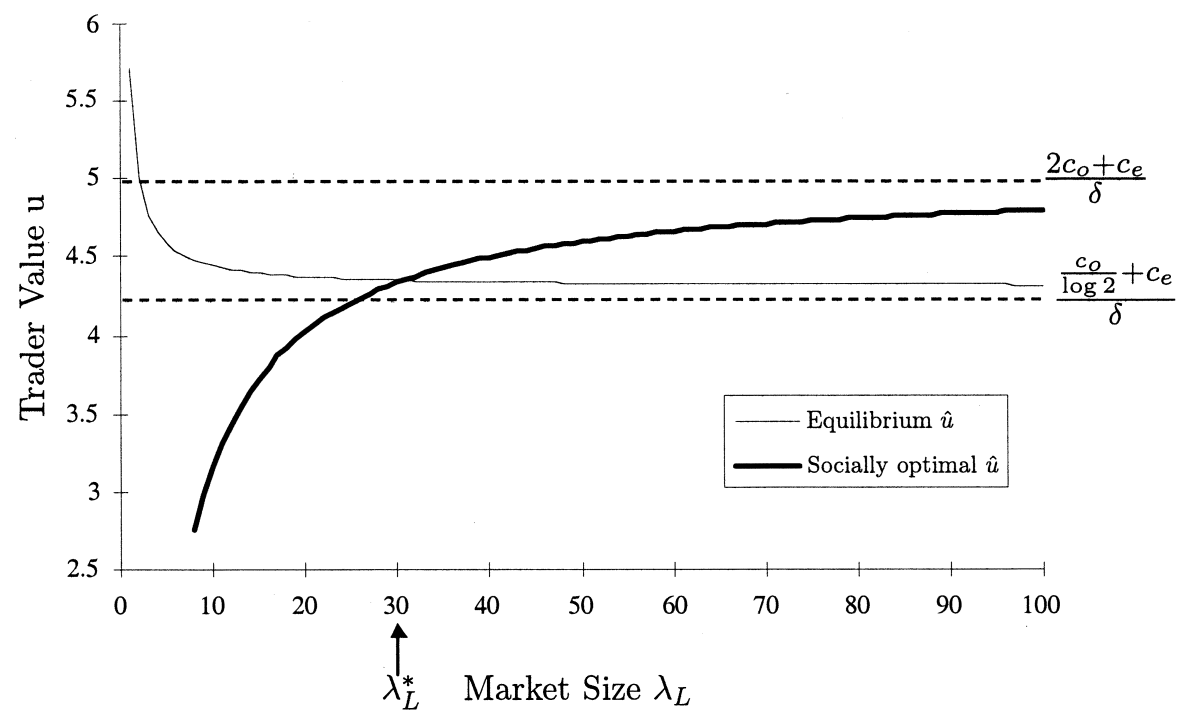

Figure 2. Socially optimal $\hat{\boldsymbol{u}}$ versus equilibrium $\hat{\boldsymbol{u}}$-liquidity versus crowding. The curves represent the equilibrium and socially optimal amounts of CN trading, represented by the respective cutoff values, $\hat{u}$, for different size markets. The equilibrium cutoff value arises from traders choosing their behavior to maximize their individual welfare, and the socially optimal cutoff value maximizes the aggregate welfare of the traders as a group. The horizontal lines represent equilibrium and socially optimal amounts of CN trading for a "thick" market. Parameter values are $c_{o}=1, c_{e}=2, F(u) \sim N(0,50), \delta=0.7, \lambda_{I}=1$, and $\sigma_{\tilde{v}}=10$.

these trades compete with higher-liquidity preference trades on the same side of the market, reducing the latter's probability of execution and lowering overall surplus.

The crowding effect is a direct result of the CN's lack of price priority. Because the CN derives its price from a primary market, rather than being responsive to the demand and supply fluctuations in the $\mathrm{CN}$ itself, higherliquidity-preference orders can fail to execute, which is reflected in our crowding effect. Whether the crowding or liquidity effect is stronger depends on the market size, $\lambda_{L}$. If the market is sufficiently "thick," then the liquidity effect is smaller than the crowding effect (see Section IV.D.2). If the market is "thin," then the liquidity effect is stronger.

Figure 2 compares the socially optimal $\hat{u}$, obtained by maximizing equation (16), and the equilibrium $\hat{u}$, given by the smaller solution to equation (15), as the expected number of buyers and sellers ranges from close to 0 to 100. As $\lambda_{L}$ tends to infinity, the socially optimal $\hat{u}$ converges to $\left(2 c_{o}+c_{e}\right) / \delta$ and the equilibrium cutoff $\hat{u}$ converges to $\left[\left(c_{o} / \log 2\right)+c_{e}\right] / \delta .{ }^{21}$ The socially optimal $\hat{u}$ is less than the equilibrium $\hat{u}$ for small $\lambda_{L}$. As $\lambda_{L}$ increases, the probability of execution increases and the adverse selection decreases in the

${ }^{21}$ Figure 2 also shows that the equilibrium $\hat{u}$ converges more quickly than the socially optimal $\hat{u}$. This follows from how quickly the $\mathrm{CN}$ becomes liquid. 
$\mathrm{CN}$, and the liquidity provided by low-liquidity preference trades becomes less valuable. For $\lambda_{L}<\lambda_{L}^{*} \approx 30$, the low-liquidity preference trades provide enough additional liquidity to overcome their crowding effect, and it is socially optimal to encourage more than the equilibrium number of traders to use the CN. For $\lambda_{L}>30$, the socially optimal $\hat{u}$ is greater than the equilibrium $\hat{u}$, meaning that it would be socially optimal to exclude some of the traders who want to trade.

Socially optimal trader behavior, the first best outcome, can be induced by charging an appropriate price. ${ }^{22}$ Whether or not that price is above or below the CN's cost depends on whether or not the liquidity or crowding externality is stronger. As seen in Figure 2, in thin enough markets $\left(\lambda_{L}<\lambda_{L}^{*}\right)$, the liquidity externality is stronger and the socially optimal price is below the CN's cost. In sufficiently "thick" markets $\left(\lambda_{L}>\lambda_{L}^{*}\right)$, the crowding externality is stronger and the socially optimal price is above cost.

Historical CN volumes have been relatively low, and traders' $c_{o}$, which include their time and communication costs, has been high, so CNs were concerned with attracting sufficient order flow to achieve critical mass. Once $\mathrm{CNs}$ are firmly established, crowding becomes an issue they will need to address through appropriate priority rules or pricing policies.

\section{Intermarket Competition}

Having developed the models for both the $\mathrm{CN}$ and the DM in isolation, we can now study their coexistence. Our analysis begins by examining traders' expected net gain, conditional on the expected actions of all other traders, from four possible trading strategies: do not attempt to trade; submit an order to the $\mathrm{CN}$ and if it fails to execute, do nothing (trade exclusively on the $\mathrm{CN}$ ); submit an order to the $\mathrm{CN}$ and if it fails to execute, trade in the DM (trade opportunistically on the $\mathrm{CN}$ ); or trade in the DM without first attempting to trade on the CN. Each trader choosing the strategy that maximizes her expected net benefit leads to a Nash Equilibrium where no trader wants to deviate given the expected actions of all other traders. Clearly, the informed traders' decisions are driven by the longevity of their information: long-lived information leads to opportunistic trading on the $\mathrm{CN}$, and shortlived information forces trading in the DM before the cross.

We analyze the impact of the CN's introduction on the dealers' spread and the possibility of market failure, discuss how the nature of the insiders' information interacts with liquidity traders' decisions and dealers' spread, examine the sensitivity of the equilibrium to the parameter values, explore the critical-mass phenomenon more fully, and discuss the appropriate measurement of trading activity in both markets.

\footnotetext{
${ }^{22}$ An analysis of optimal pricing is complex, because traders' decisions are an implicit function of price. The socially optimal price can be found by taking the socially optimal $\hat{u}$, which equates equation (17) to zero, and substituting it into the left-hand side of equation (15). Using this value in place of $c_{o}$ in equation (15) will induce the socially optimal $\hat{u}$. As $\lambda_{L} \rightarrow \infty$, any combination of execution and submission prices that results in an expected total charge of $\left(2 \cdot c_{o}+c_{e}\right) \cdot \log 2-c_{o}$ is socially optimal.
} 


\section{A. Liquidity Trader Segmentation and Equilibria}

We denote the dealers' half-spread in the presence of a $\mathrm{CN}$ by $s$. Conditional on $s$, the equilibria are characterized by three cutoff values, $\hat{u}_{1}, \hat{u}_{2}$, and $\hat{u}_{3}$, that segment the liquidity traders into four (some possibly empty) sets based on the strength of their liquidity preference:

- Traders in Segment $I, u<\hat{u}_{1}$, do not trade at all.

- Traders in Segment II, $\hat{u}_{1} \leq u \leq \hat{u}_{2}$, trade exclusively on the CN.

- Traders in Segment III, $\hat{u}_{2}<u<\hat{u}_{3}$, use the CN opportunistically.

- Traders in Segment $I V, u \geq \hat{u}_{3}$, trade immediately in the DM.

At the cutoff values, liquidity traders are indifferent between $\left(\hat{u}_{1}\right)$ not trading and trading exclusively on the $\mathrm{CN} ;\left(\hat{u}_{2}\right)$ using the $\mathrm{CN}$ exclusively and opportunistically; and $\left(\hat{u}_{3}\right)$ optimally using the CN and going directly to the DM. The equilibrium equations for $\underline{\hat{u}}=\left(\hat{u}_{1}, \hat{u}_{2}, \hat{u}_{3}\right)$ depend on the surplus that traders receive from following the four possible strategies. This segmentation determines the probability of execution in the CN with the fraction of liquidity traders being $\bar{F}\left(\hat{u}_{1}\right)-\bar{F}\left(\hat{u}_{3}\right)$. The insiders trade on the CN with probability $(1-\gamma)$; we thus distinguish between the probability of execution on the CN without the insiders, $P(\operatorname{trade} \mid L, \underline{\hat{u}})$, given by equation (10), and the probability of execution on the $\mathrm{CN}$ with the insiders, $P(\operatorname{trade} \mid I, \underline{\hat{u}})$, which is given by the average of equations (13) and (14). The unconditional probability of execution in the $\mathrm{CN}$ is given by the weighted average, $P(\operatorname{trade} \mid \underline{\hat{u}})=\gamma \cdot P(\operatorname{trade} \mid L, \underline{\hat{u}})+(1-\gamma) P(\operatorname{trade} \mid I, \underline{\hat{u}})$.

A liquidity trader with value $u$ has a zero expected net gain from not trading. Her expected net gain from using the CN exclusively is $\left(\delta \cdot u-c_{e}\right)$. $P(\operatorname{trade} \mid \underline{\hat{u}})-c_{o}-\sigma_{\tilde{v}}(1-\gamma)\left(P\left(\operatorname{trade} \mid I_{0}, \underline{\hat{u}}\right)-P\left(\operatorname{trade} \mid I_{1}, \underline{\hat{u}}\right)\right)$. If she uses the CN opportunistically, she gains that same amount plus $\delta \cdot u-s+$ $\sigma_{\tilde{v}}(1-\gamma)\left(P\left(\operatorname{trade} \mid I_{0}, \underline{\hat{u}}\right)-P\left(\operatorname{trade} \mid I_{1}, \underline{\hat{u}}\right)\right)$ when she does not find a match on the CN and proceeds to the DM. A trader who uses the CN opportunistically can use the information she learns from the outcome of her own trade on the $\mathrm{CN}$ to lessen her adverse selection costs. In particular, if she proceeds to the DM, the informed traders are more likely to be on her side of the market.

We define $\hat{u}_{1}, \hat{u}_{2}$, and $\hat{u}_{3}$ as the solutions to the following system of equations:

$$
\begin{gathered}
\left(\delta \cdot \hat{u}_{1}-c_{e}\right) \cdot P(\operatorname{trade} \mid \underline{\hat{u}})=c_{o}+\sigma_{\tilde{v}}(1-\gamma)\left(P\left(\operatorname{trade} \mid I_{0}, \underline{\hat{u}}\right)-P\left(\operatorname{trade} \mid I_{1}, \underline{\hat{u}}\right)\right), \\
\left(\delta \cdot \hat{u}_{2}-c_{e}\right) \cdot P(\operatorname{trade} \mid \underline{\hat{u}})-\sigma_{\tilde{v}}(1-\gamma)\left(P\left(\operatorname{trade} \mid I_{0}, \underline{\hat{u}}\right)-P\left(\operatorname{trade} \mid I_{1}, \underline{\hat{u}}\right)\right) \\
\quad=\left(\delta \cdot \hat{u}_{2}-c_{e}\right) \cdot P(\operatorname{trade} \mid \hat{\underline{u}})+\left(\delta \cdot \hat{u}_{2}-s\right)(1-P(\operatorname{trade} \mid \underline{\hat{u}}))
\end{gathered}
$$

which simplifies to $\hat{u}_{2}=\frac{s-\Delta}{\delta}$ where $\Delta=\sigma_{\tilde{v}}(1-\gamma)\left(\frac{P\left(\operatorname{trade} \mid I_{0}, \hat{\underline{u}}\right)-P\left(\operatorname{trade} \mid I_{1}, \hat{u}\right)}{1-P(\operatorname{trade} \mid \hat{u})}\right)$, and

$$
\hat{u}_{3}-s=\left(\delta \cdot \hat{u}_{3}-c_{e}\right) \cdot P(\operatorname{trade} \mid \underline{\hat{u}})+(1-P(\operatorname{trade} \mid \hat{\hat{u}}))\left(\delta \cdot \hat{u}_{3}-s\right)^{+},
$$


where $\left(\delta \cdot \hat{u}_{3}-s\right)^{+}=\max \left\{0, \delta \cdot \hat{u}_{3}-s\right\}$. Because traders will only go on to the $\mathrm{DM}$ after first attempting to trade on the $\mathrm{CN}$ if their value is greater than $\hat{u}_{2}$, equation (21) can be broken down into two possibilities depending on whether $\hat{u}_{2}$ is less than or greater than $\hat{u}_{3}$. If $\hat{u}_{3}<\hat{u}_{2}$, then equation (21) becomes

$$
\hat{u}_{3}-s=\left(\delta \cdot \hat{u}_{3}-c_{e}\right) \cdot P(\operatorname{trade} \mid \underline{\hat{u}})
$$

and if $\hat{u}_{3}>\hat{u}_{2}$, equation (21) becomes

$$
\hat{u}_{3} \cdot(1-\delta)=\left(s-c_{e}\right) \cdot P(\text { trade } \mid \underline{\hat{u}}),
$$

because the trader loses $1-\delta$ of her value by waiting and saves $s-c_{e}$ when she trades on the CN.

Each trader selects the strategy that maximizes her expected net gain, conditional on the expected actions of all other traders. Any set of strategies that no trader has any incentive to unilaterally deviate from is a Nash Equilibrium. Even though the equilibrium is typically not unique, all equilibria have the common structure outlined above. The parameters of the model may lead to some of the segments being empty; for example, if the $\mathrm{CN}$ is too expensive, traders may use it only exclusively, only opportunistically, or not at all. No opportunistic-CN trading is driven primarily by $\delta$ being too low; no exclusive-CN trading is caused by too much adverse selection in the $\mathrm{CN}$; and no $\mathrm{CN}$ trading of either kind is caused by a combination of the previous two factors and high order cost, which together can prevent the CN from achieving critical mass. When the adverse selection costs are too large in equation (19) for any traders to use the CN exclusively, the equilibrium equations are given by the conditions that (i) a trader is indifferent between using the CN opportunistically and going directly to the DM, equation (23), and (ii) a trader is indifferent between using the CN opportunistically and not trading at all, namely,

$$
\left(\delta \cdot \hat{u}_{2}-c_{e}\right) \cdot P(\operatorname{trade} \mid \underline{\hat{u}})+\left(\delta \cdot \hat{u}_{2}-s\right)(1-P(\operatorname{trade} \mid \underline{\hat{u}}))-c_{o}=0 .
$$

If the $\mathrm{CN}$ is unable to achieve critical mass, the equilibrium is given by the analysis in Section II. The general structure of the equilibria is given by the following proposition.

Proposition 7: All equilibria have the structure that a liquidity trader with value $u$ will choose from the following strategies:

Segment I: $\quad$ Do not trade

Segment II: Trade only on the CN

Segment III: Attempt to trade on the CN, then go to the DM if $\hat{u}_{2}<u<\hat{u}_{3}$,

Segment IV: Trade in the DM

$$
\begin{aligned}
& \text { if } u<\hat{u}_{1}, \\
& \text { if } \hat{u}_{1} \leq u \leq \hat{u}_{2}, \\
& \text { if } \hat{u}_{2}<u<\hat{u}_{3}, \\
& \text { if } u \geq \hat{u}_{3},
\end{aligned}
$$


where $(i)$ if any traders use the $C N$ exclusively $\left(\hat{u}_{1}<\hat{u}_{2}\right), \hat{u}_{1}$ and $\hat{u}_{3}$ are the solutions to equations (19) and (21) and $\hat{u}_{2}=\min$ (solution to equation (20), $\hat{u}_{3}$ ), (ii) if no traders use the $C N$ exclusively and some traders use the CN opportunistically $\left(\hat{u}_{2}<\hat{u}_{3}\right), \hat{u}_{2}$ and $\hat{u}_{3}$ are the solutions to equations (23) and (24) and $\hat{u}_{1}=\hat{u}_{2}$, and (iii) if no traders use the $C N, \hat{u}_{3}=s_{D}+c_{o}$ where $s_{D}$ is given in equation (5) and $\hat{u}_{1}=\hat{u}_{2}=\hat{u}_{3}$.

Further discussion of these equilibria is deferred until we determine how the liquidity traders' decisions affect the DM.

\section{B. Equilibrium in the Dealer Market-Effects of the CN}

The above analysis was conditional on the dealers' half-spread. However, the introduction of the CN affects the dealers' costs, hence the outcome of their competition-both the number of dealers and the spread. In particular, the order flow faced by the DM is affected by the transactions between long-lived informed orders, exclusive-CN orders, and opportunistic-CN orders. In this section, we take the equilibrium cutoff values, $\underline{\hat{u}}$, as given, and find the competitive outcome in the DM. This will then be combined with the analysis in Section IV.A to fully characterize the equilibrium when the DM and the CN compete.

Let $\alpha_{i}$ be the probability that a liquidity trader is in Segment $i(i=I, I I$, $I I I, I V)$ and let $\underline{\alpha}=\left(\alpha_{I}, \alpha_{I I}, \alpha_{I I I}, \alpha_{I V}\right)$. By Lemma 1 , the expected number of liquidity traders of each type is the above fraction times $\lambda_{L}$. Before examining the DM under this segmentation, we consider a baseline case with a $\mathrm{DM}$ and no $\mathrm{CN}$ but with a particular order flow reflecting the fact that the exclusive-CN orders never go to the DM. Specifically, the exclusive-CN orders are not submitted to the DM, and the informed, dealer-only, and opportunistic-CN liquidity orders are. This baseline case is useful for studying the CN's effects on the DM while holding order flow constant. Because in this section we are assuming a fixed segmentation $(\underline{\alpha})$ of liquidity traders, comparisons with the baseline case will not take into account changes in liquidity traders' decisions. These effects will be discussed after laying the groundwork for how the $\mathrm{CN}$ affects dealer competition.

In the baseline case, the dealers expect to receive $E\left[D_{I}\right]=\lambda_{I}+\left(\alpha_{I I I}+\alpha_{I V}\right) \lambda_{L}$ units on the informed side and $E\left[D_{L}\right]=\left(\alpha_{I I I}+\alpha_{I V}\right) \lambda_{L}$ units on the liquidity side. Using this order flow, the baseline case can be solved using the results in Section II. Keeping the no-CN case in mind, we turn to examining how the use of the CN affects the dealers' inventory risk and order flow.

When the information is short lived (long lived), the dealers expect to receive $E\left[D_{I}^{S}\right]\left(E\left[D_{L}^{S}\right]\right)$ units on the informed side and $E\left[D_{L}^{S}\right]\left(E\left[D_{L}^{L}\right]\right)$ on the liquidity side. The dealers' order flow differs from the CN because the opportunistic-CN orders and, in the case of long-lived information, the informed orders may now trade in the $\mathrm{CN}$ and never go to the DM. These effects are summarized in the following proposition.

Proposition 8: The CN's introduction has the following impact on the dealers' order flow and costs as compared to the baseline case: 
1. The expected number of units on the informed and liquidity sides traded in the $D M$ is smaller, $\left.\gamma \cdot E\left[D_{I}^{S}\right]+(1-\gamma) E\left[D_{I}^{L}\right]\right) \leq E\left[D_{I}\right]$ and $\left.\gamma \cdot E\left[D_{L}^{S}\right]+(1-\gamma) E\left[D_{L}^{L}\right]\right) \leq E\left[D_{L}\right]$, with the difference increasing in the amount of opportunistic-CN trading. The expected number of units is smaller with long-lived information than with short-lived information, $E\left[D_{I}^{L}+D_{L}^{L}\right] \leq E\left[D_{I}^{S}+D_{L}^{S}\right]$.

2. The dealers' inventory risk is reduced by $C N$ trading due to risk sharing on opportunistic-CN orders and non-exclusive-CN orders trading with the exclusive-CN orders. These effects are stronger with long-lived information.

3. The dealers' expected adverse selection costs with the $C N$ are not changed when the information is short lived but are lower when the information is long lived, $E\left[D_{I}^{S}-D_{L}^{S}\right]=E\left[D_{I}-D_{L}\right] \leq E\left[D_{I}^{L}-D_{L}^{L}\right]$, with the difference increasing in the amount of exclusive-CN trading.

Part 1 of Proposition 8 shows how the possibility of orders trading on the CN, rather than going to the DM, reduces the dealers' order flow, with the reduction increasing in the number of exclusive- $\mathrm{CN}$ and opportunistic-CN orders. Part 2 demonstrates how exclusive liquidity traders transacting with other traders on the $\mathrm{CN}$ reduces the total risk. The $\mathrm{CN}$ creates an interesting risksharing benefit for the DM: opportunistic orders going to the DM after failing to match on the $\mathrm{CN}$ must all be on the same side of the market-in effect, sharing the risk from the opportunistic-CN orders across dealers. Thus, the Reiss and Werner (1998) risk-sharing benefit studied in Section II is realized by pooling orders on the $\mathrm{CN}$ without requiring interdealer trading. ${ }^{23}$ If the dealers explicitly share inventory risk by trading, this benefit disappears. Finally, Part 3 shows how long-lived informed trading with exclusive-CN orders can reduce the expected order imbalance faced by the dealers. On one hand, this lowers dealers' adverse-selection costs while reducing price efficiency. On the other hand, the reduction in the liquidity order flow to the DM (Part 1) increases dealers' adverse selection while improving price efficiency.

Proposition 8 shows how the CN reduces the dealers' costs but also reduces their order flow, making the net effect on dealers' average cost and price efficiency ambiguous. In addition, it shows how increasing the longevity of inside information increases the CN's impact and how the effect of liquidity trading depends on the nature of the information. We can now analyze the effect of competition between the CN and the DM on the dealer spread.

\section{DM with CN, Conditional on Liquidity Traders' Strategies}

Proposition 9: Conditional on the liquidity traders' strategies, in the presence of the CN, the unique Nash Equilibrium is for

$$
n=\sqrt{\frac{k}{A}} \cdot \sqrt{E\left[J_{D}{ }^{2}\right]-E\left[D_{I}+D_{L}\right]+(1-\gamma) \cdot \psi^{L}+\gamma \cdot \psi^{S}},
$$

${ }^{23}$ The CN's structure also makes it an ideal mechanism for facilitating risk-sharing interdealer trading. 
dealers to trade expected quantity

$$
q=\frac{\gamma \cdot E\left[D_{I}^{S}+D_{L}^{S}\right]+(1-\gamma) \cdot E\left[D_{I}^{L}+D_{L}^{L}\right]}{n}
$$

each by quoting the identical half-spread given by the smallest root of

$$
\begin{aligned}
s= & \sigma_{\tilde{v}} \cdot \frac{\gamma \cdot E\left[D_{I}^{S}-D_{L}^{S}\right]+(1-\gamma) E\left[D_{I}^{L}-D_{L}^{L}\right]}{\gamma \cdot E\left[D_{I}^{S}+D_{L}^{S}\right]+(1-\gamma) E\left[D_{I}^{L}+D_{L}^{L}\right]}+\frac{2 \cdot A}{q} \\
& +k\left(1-\frac{(1-\gamma)\left(E\left[D_{I}^{S}-D_{L}^{S}\right]-E\left[D_{I}^{L}-D_{L}^{L}\right]\right)}{\left(\gamma \cdot E\left[D_{I}^{S}+D_{L}^{S}\right]+(1-\gamma) E\left[D_{I}^{L}+D_{L}^{L}\right]\right)}\right),
\end{aligned}
$$

where $\psi^{L}$ and $\psi^{S}$ are defined in the Appendix.

Similar to Proposition 1, the spread has three components: adverse selection; fixed and quadratic inventory costs; and linear inventory costs. The linear inventory cost is reduced by the amount that the expected dealer imbalance is decreased due to long-lived information trading in the $\mathrm{CN}$, divided by the expected order flow to the DM. The adverse selection and the fixed and quadratic inventory components may increase or decrease, depending on the relative magnitudes of the different liquidity-trader segments.

Although the effect of introducing the $\mathrm{CN}$ can be ambiguous, under certain conditions it can only increase the spread. In particular, as shown below, if the CN does not attract "new" orders that would not have gone to the DM without the $\mathrm{CN}$, and the information is short lived or there is no exclusive-CN usage, then the CN's introduction causes dealers to widen their spread.

Proposition 10: Assume that the total order flow is the same as in the dealeronly case. If the information is short lived, the spread is increasing in the amount of liquidity trading on the CN (in particular, the spread is higher with the CN). If the information is long lived and no traders use the CN exclusively, then the spread is higher with the CN.

Proposition 10 shows that the inventory risk reduction in Proposition 8 never lowers the dealers' costs enough to offset the loss of order flow. When information is short lived or there is no exclusive-CN trading, there is no reduction in adverse-selection cost, and the spread must widen.

As previously noted, concerns about adverse selection in the $\mathrm{CN}$, due to long-lived information, led some CNs to limit usage to "passive" institutions that are more likely to engage in liquidity trading. This forces all informed trading into the DM. One might expect this restriction to lead to a higher dealer spread due to adverse selection. However, the following proposition gives a simple condition sufficient to guarantee that forcing the informed traders to go to the DM leads to a smaller spread.

Proposition 11: If no traders use the CN exclusively, then the number of dealers and the spread are lower when the information is short lived. 
Proposition 11's surprising result follows from the fact that when there is no exclusive-CN trading, allowing the informed traders to enter the CN does not provide any adverse-selection benefits and the large reduction in order flow offsets any inventory risk reduction. This causes the number of dealers and the spread to be decreasing in $\gamma$.

The overall equilibria are obtained by combining the analyses in Sections IV.A and IV.C. We next turn to these equilibria.

\section{Equilibria with $C N$ and $D M$}

Together, Propositions 7 and 9 characterize the equilibrium when the DM competes with the CN. Although the system of nonlinear equations that determine the equilibria is difficult to solve, we can derive a number of its behavioral implications. Because a trader with $u=s_{D}+c_{o}$ is indifferent between trading in the DM and not trading, the CN appeals most to traders with liquidity preferences around $s_{D}+c_{o}$. If the $\mathrm{CN}$ cannot induce these traders to join it, then no traders will use it and critical mass cannot be reached. In general, the critical-mass phenomenon has the same form as without the competing DM: the CN must attract sufficient volume before any traders will use it.

If the adverse selection on the $\mathrm{CN}$ is too great, liquidity traders can decide ex ante to go to the DM, where execution is guaranteed and the adverseselection cost may be lower. This may lead to the exclusive-CN segment being empty. If the implicit cost of waiting to trade is high (i.e., $\delta$ is low compared to the expected cost savings from trading on the $\mathrm{CN}$ ), then exclusive or DM trading is preferable to opportunistic-CN trading, leaving the opportunistic-CN segment empty. Also, if the probability of execution is too low, the $\mathrm{CN}$ will fail to attract enough volume to achieve critical mass, and no traders will use it.

The equilibria exhibit the same "crowding" effect as the CN-only case (Section III.C), with low-net-gain traders crowding out high-net-gain traders on the $\mathrm{CN}$. In this case, however, the net gains are relative rather than absolute, as they measure the relative gain from choosing to go to the $\mathrm{CN}$ over the DM or not trading. With competing markets, the crowding effect is even stronger, because from an overall welfare perspective there are two types of low-net-gain trades on the CN. The first type includes those who expect small gains from trading on the $\mathrm{CN}$ relative to not trading at all. As with only the CN, as a group these traders overestimate the probability that their trades will be executed and hence pay $c_{o}$ more often than is socially optimal. The second type includes those who expect small gains from trading on the $\mathrm{CN}$ relative to the DM. Traders in this group do not pay $c_{o}$ too often, but rather they wait for the $\mathrm{CN}$ when, as a group, they would be better off if the highest-value traders went directly to the DM. ${ }^{24}$

Traders using the CN change the size and composition of the DM's order flow. In the extreme, the $\mathrm{CN}$ can attract so many of the liquidity traders that the DM will fail. However, the reverse can also occur: the CN can in-

${ }^{24}$ As seen in Section IV.D.2, these traders cause crowding even if $c_{o}=0$, because the probability of execution affects their choice between using the CN and the DM. 
crease the order flow going to the DM, making it possible for the DM to survive where it would otherwise fail (see Section IV.B).

We next show how the equilibria are affected by market characteristics, analyze special cases where the equilibria can be derived in closed form, and point out some measurement issues.

\section{D.1. Sensitivity Analyses}

Increasing the order $\left(c_{o}\right)$ or execution costs $\left(c_{e}\right)$ diminishes the amount of exclusive-CN trading, further reducing $\mathrm{CN}$ trading. Increasing the dealers' costs (either the fixed cost $A$ or the inventory cost $k$ ) has the opposite effect: as more traders use the $\mathrm{CN}$, it becomes more liquid, attracting additional traders due to the liquidity externality. More patient liquidity traders (higher $\delta$ ) heighten the appeal of opportunistic-CN trading, improving the CN's liquidity and making the CN more attractive. If there is any exclusive-CN trading, increasing the longevity of the insiders' information (decreasing $\gamma$ ) raises the adverse-selection costs of exclusive- $\mathrm{CN}$ trading and lowers the adverse-selection component of the dealers' spread, inducing some opportunistic-CN traders to go directly to the DM and causing some exclusive-CN traders to stop trading and others to use the CN opportunistically. Decreasing the amount of informed trading, $\lambda_{I}$, decreasing the volatility, $\sigma_{\tilde{v}}$, or increasing the amount of liquidity trading, $\lambda_{L}$, lowers adverse selection in both the $\mathrm{CN}$ and the DM, allowing the magnitude of the various segments to either increase or decrease. Increasing the amount of liquidity trading has the same effect, but it also increases the probability of execution in the $\mathrm{CN}$, which, again, draws more traders to it.

\section{D.2. Equilibrium in a Thick Market}

As with the CN only, in a "thick" market, as $\lambda_{L} \rightarrow \infty$, the adverse-selection, liquidity externality, and critical-mass phenomena disappear. The probability of execution approaches log 2 regardless of any individual trader's decision: there are so many traders that even if only a small fraction go to the $\mathrm{CN}$, it will still be liquid. This reduces the number of equilibria to at most two: one that is stable with the $\mathrm{CN}$ having positive order flow and the other where no traders use the $\mathrm{CN}$, which is unstable (unless it is the unique equilibrium). For the remainder of this subsection, we focus on the former equilibrium and analyze two limiting cases: where the $\mathrm{CN}$ does not attract any opportunistic traders and where $\delta=1$.

\section{No Opportunistic-CN Traders}

If $\hat{u}_{3}<s_{D} / \delta$ and $s_{D}>c_{e} / \delta$ the structure of the equilibrium guarantees that some traders will use the CN exclusively and none will use it opportunistically. ${ }^{25}$ Without any opportunistic-CN traders, the dealers' half-spread is $s=$

\footnotetext{
${ }^{25}$ Explicit regulation or trading rules could also ensure that traders do not use the DM as a "market of last resort."
} 
$s_{D}$ and the equilibrium equations are (19) and (22). The resulting equilibrium is described in the following proposition, which is proved by taking the limits of equations (19) and (22) as $\lambda_{L} \rightarrow \infty$.

Proposition 12: In a "thick" market, if the opportunistic-CN segment is empty and the CN attracts some volume, the unique stable Nash Equilibrium has the structure described in Proposition 7 with the cutoff values

$$
\hat{u}_{1}=\frac{1}{\delta}\left(c_{e}+\frac{c_{o}}{\log 2}\right), \quad \hat{u}_{2}=\hat{u}_{3}=\frac{s_{D}-c_{e} \log 2}{1-\delta \log 2}
$$

From equation (27), we can see that in a "thick" market, the opportunistic-CN segment is empty $\left(\hat{u}_{2}>\hat{u}_{3}\right)$ if and only if $s_{D}<\delta c_{e} \log 2 /[\delta(1+\log 2)-1] .{ }^{26}$ In equation (27), $\hat{u}_{1}\left(\hat{u}_{3}\right)$ is linear in both $c_{e}$ and $c_{o}\left(s_{D}\right)$. By contrast, $\hat{u}_{1}\left(\hat{u}_{3}\right)$ is a convex and decreasing (increasing) function of $\delta$, making the equilibrium sensitive to traders' impatience. Although in this case the distribution of values does not affect the equilibrium cutoff values, $F(\cdot)$ does affect the relative sizes of the different segments.

Finally, in this case the crowding effect (Proposition 6) exists even when $c_{o}=0$. The expected fraction of $\mathrm{CN}$ orders that trade is $1 / 2$, which is less than the probability of execution, $\log 2$, and the socially optimal cutoff values are $\hat{u}_{1}^{S O C}=c_{e} / \delta=\hat{u}_{1}$ and $\hat{u}_{3}^{S O C}=\left(s_{D}-c_{e} / 2\right) /(1-\delta / 2)>\hat{u}_{3}$. Because the liquidity traders are overly optimistic, from a $\mathrm{CN}$-wide perspective, that their trades will execute, some choose to use the CN when social welfare would be improved if they went to the DM. Here, the liquidity externality has no impact, and the CN always becomes overcrowded.

\section{Time-Insensitive Traders}

In this section we consider the case where traders are not time sensitive, $\delta=1 .{ }^{27}$ If any trades occur on the $\mathrm{CN}$, that is, $s>c_{e} \cdot \log 2$, all liquidity traders prefer to go to the $\mathrm{CN}$ before trading in the DM. The stable equilibrium is then given by the following proposition, which is proved by taking the limit of equation (19) as $\lambda_{L} \rightarrow \infty$ and noting that because there is no solution to equations $(22)$ or $(23), \hat{u}_{3}=\infty$.

Proposition 13: In a "thick" market with $\delta=1$, if the $C N$ attracts positive volume, the unique stable Nash Equilibrium has the structure described in Proposition 7 with the DM segment being empty, $\hat{u}_{3}=\infty$, and

$$
\hat{u}_{1}=c_{e}+\frac{c_{o}}{\log 2}, \quad \hat{u}_{2}=s=2\left(s_{D}-k\right)+k=2 \sqrt{2 \cdot A \cdot k}+k
$$

\footnotetext{
${ }^{26}$ If the opportunistic-CN segment is not empty, then $\hat{u}_{1}$ remains as in equation (27), $\hat{u}_{3}=$ $\frac{\left(s-c_{e}\right) \log 2}{1-\delta}$, and $s$ (and $\left.\hat{u}_{2}\right)$ are implicitly defined by $s=\frac{s_{D} \cdot 2 \vec{F}\left(\hat{u}_{2}\right)}{\bar{F}\left(\hat{u}_{2}\right)+\bar{F}\left(\hat{u}_{3}\right)}$.

27 This may correspond to the $\mathrm{CN}$ crossing with a high frequency.
} 
Table I

\section{Example: Comparing the Equilibria with and without the CN}

Below are the equilibria in terms of the dealer half-spread ( $s$ and $s_{D}$ ), fraction of liquidity traders following different trading strategies $\left(\bar{F}\left(s_{D}+c_{o}\right)\right.$ and $\alpha_{I I}, \alpha_{I I I}$, and $\left.\alpha_{I V}\right)$, and subsequent price volatility $\left(\sigma_{\tilde{v}}^{p}\right)$ with and without the presence of the CN. Parameter values are $c_{o}=0$, $c_{e}=2, F(u) \sim N(0,100), \delta=0.76, \gamma=1, \lambda_{L}=10, \lambda_{I}=5, \sigma_{\tilde{v}}=50, A=1$, and $k=0.1$.

\begin{tabular}{ccccccccc}
\hline \multicolumn{3}{c}{ Equilibrium without CN } & & \multicolumn{5}{c}{ Equilibrium with CN } \\
\cline { 6 - 9 }$s_{D}$ & $\bar{F}\left(s_{D}+c_{o}\right)$ & $\sigma_{\tilde{v}}^{p}$ & & $s$ & $\alpha_{I I}$ & $\alpha_{I I I}$ & $\alpha_{I V}$ & $\sigma_{\tilde{v}}^{p}$ \\
\hline 11.36 & 0.91 & 48.01 & & 11.90 & 0.10 & 0.05 & 0.82 & 47.87 \\
\hline
\end{tabular}

By equation (28), all traders with values less than the expected cost divided by the probability of execution, $\log 2$, will submit orders to the CN, and traders with values above the dealers' half-spread, $2\left(s_{D}-k\right)+k$, will subsequently trade with a dealer if they fail to find a match on the CN. In addition, equation (28) shows that the CN's introduction causes the fixed and quadratic inventory cost components of the spread to double while leaving the linear inventory component unchanged.

\section{D.3. Trades versus Orders}

Because not all trades that go to the $\mathrm{CN}$ execute there, trading volume on the $\mathrm{CN}$ underestimates its overall impact on the marketplace. We next analyze this disparity, showing that less than 50 percent of $\mathrm{CN}$ order volume is actually reported as $\mathrm{CN}$ trades.

Proposition 14: The ratio of the expected $C N$ trading volume to the expected order flow submitted to the CN is less than 1/2. The smaller the liquidity order flow to the $\mathrm{CN}$, the lower this ratio.

Unlike the CN, all orders going to the DM are executed; hence the order and trading volumes are identical in the DM. In the extreme case where all traders use the $\mathrm{CN}$ opportunistically, all orders first go to the $\mathrm{CN}$, with at least $1 / 2$ of them going to the DM after failing to find a match in the CN. Then, while all orders go to the $\mathrm{CN}$, the DM will report a higher volume. Thus, comparing the trading volumes of the two markets must be approached carefully. Because only trading volume is commonly reported, the importance of CNs can easily be underestimated.

Table I presents a simple numerical example, where the CN attracts 12 percent of the order flow but reports only five percent of trading volume. Without the CN, 91 percent of liquidity traders participate; the CN increases liquidity-trader participation to 97 percent. Here, the liquidity traders that stop going directly to the DM, nine percent, are almost evenly split between using the CN exclusively and opportunistically. Even though the trading volume on the $\mathrm{CN}$ is relatively small, the introduction of the $\mathrm{CN}$ increases the spread by almost five percent. In addition, the CN's introduction increases the 
reduction in the expected posterior value volatility, $\sigma_{\tilde{v}}-\sigma_{\tilde{v}}^{p}$, by almost seven percent, illustrating how wider dealer spreads due to the $\mathrm{CN}$ are typically accompanied by more efficient prices.

\section{E. Effects of the CN on the Dealer Market in Equilibrium}

Having derived the equilibria with competing markets, we now examine how the CN-induced changes in traders' behavior affect the DM. Because our model allows both traders' choices and the DM to adjust, the introduction of the CN has multiple effects on the DM. First, allowing liquidity traders to use the $\mathrm{CN}$ opportunistically rather than go directly to the DM tends to widen dealers' spread and increase price efficiency. On the other hand, the $\mathrm{CN}$ attracts liquidity traders who would not otherwise trade. This decreases price efficiency and can lower the spread when the insiders' information is long lived, although the spread effect is not strong enough (i.e., the CN always raises the spread) when the information is short lived. Third, liquidity traders' choice to use the CN opportunistically or exclusively can either widen or narrow the spread and increase or decrease price efficiency, depending on circumstances. These sometimes conflicting effects are important when considering the overall impact of the $\mathrm{CN}$ on the dealer market.

With the full equilibrium defined, we can analyze the effects of the $\mathrm{CN}$ on the DM while taking into account the changes in liquidity traders' behavior. Of particular interest are the competing effects of the $\mathrm{CN}$ possibly reducing dealers' adverse selection through attracting "new" liquidity traders (with $u<s_{D}+c_{o}$ ), and, in the case of long-lived information, reducing the amount of informed trading in the DM, versus the "cream-skimming" of matching trades. While discussing how the previous partial equilibrium results hold in the full equilibrium, we will explore the effects of the $\mathrm{CN}$ on the dealers' spread and price efficiency and how the liquidity traders' behavior interacts with the nature of the information to impact the DM.

As shown in the proposition below, with no informed trading, the negative "cream-skimming" effect dominates the positive effect of attracting new order flow. This is due to the CN's negative impact on dealers' inventory and fixed costs and to the fact that orders first going to the CN impose higher costs on the DM than those going directly to the DM.

Proposition 15: If there are no informed traders, then the spread is increasing in the amount of trading on the CN and is higher than without the CN.

Traders who fail to find a match on the CN and then use the DM as a "market of last resort" increase the dealers' risk per trade, causing them to widen their spread: the CN is "cream-skimming" the trades where counterparties are available. ${ }^{28}$ Because the $\mathrm{CN}$ matches orders passively, the vol-

\footnotetext{
${ }^{28}$ If the CN can choose to keep the informed traders out, it can also be thought of as skimming off the uninformed trades. Interestingly, as we see in subsequent examples, this type of "cream-skimming" need not lead to higher dealer spreads because of the CN's ability to attract
} 
ume traded on the $\mathrm{CN}$ is directly related to the dealers' expected imbalance per order. If the expected imbalance per order is small, dealers can amortize their costs over many orders, narrowing their spread. However, order flow from the $\mathrm{CN}$ leaves the DM with fewer orders to cover the inventory and fixed costs, leading to wider spreads.

With short-lived information, low order-submission costs are sufficient to guarantee that no new liquidity traders will be attracted to the DM. In this case, the entire new order flow goes exclusively to the CN. With short-lived information, the exclusive-CN trading does not interact with the informed trading and does not lower adverse selection (Part 3 of Proposition 8), raising the inventory and fixed costs (as in Proposition 15) and leading to higher spreads. This is summarized in the following proposition.

PRoposition 16: If the information is short lived and $c_{o}=0$, then the spread is higher with the CN than without it.

With short-lived information and low order-submission costs, the introduction of the $\mathrm{CN}$ reduces the liquidity order flow to the DM without affecting the flow of informed orders. Numerous numerical experiments have shown that the $\mathrm{CN}$ reduces value volatility and increases price efficiency. This reflects two opposite effects. First, the value volatility conditional on the order imbalance is reduced for any given imbalance. Second, the variance of the order imbalance decreases, corresponding to a reduction in the frequency of larger, more informative order imbalances. Numerically, the first effect prevails.

Because exclusive-CN trading lowers adverse selection with long-lived information, there is no direct long-lived information analog to Proposition 16. Numerical calculations show that under most circumstances, the introduction of the $\mathrm{CN}$ increases dealer spreads and decreases post-trading value volatility (increasing subsequent price efficiency). However, there are instances where the the CN's low cost can attract enough additional liquidity trading to increase post-trading value volatility and reduce adverse selection sufficiently to offset the inventory and fixed-costs effects (Proposition 15), leading to lower spreads and less efficient subsequent dealer prices. The CN's attracting new orders is a necessary, but not sufficient, condition for lower spreads. Eliminating the CN's negative inventory and fixed-costs effects ensures that if the $\mathrm{CN}$ increases order flow to the $\mathrm{DM}$, the dealer spread and price efficiency decrease. Thus, we focus on the case of no inventory or fixed costs, where the spread is simply the adverse-selection component of equation (26), $\sigma_{\tilde{v}}$ times the expected order imbalance divided by the expected order flow. ${ }^{29}$

additional liquidity traders. This may be related to the inability of empirical studies to find evidence of increased spreads due to such "cream-skimming" (Battalio (1997), Battalio, Greene, and Jennings (1997)).

${ }^{29}$ Here, the number of dealers is irrelevant as long as at least two are present to guarantee Bertrand competition. 
The first pair of rows in Table II provides examples where the CN leads to lower spreads and less efficient prices regardless of the longevity of the information. Because there is no exclusive-CN trading, $\alpha_{I I}=0$, when the information is long lived, the $\mathrm{CN}$ does not reduce the expected adverseselection costs to the dealer, $E\left[D_{I}-D\right]_{L}=E\left[D_{I}^{S}-D_{L}^{S}\right]=E\left[D_{I}^{L}-D_{L}^{L}\right]=\lambda_{I}$. In the first two examples, the DM-only liquidity trading volume is low and the CN's introduction increases the dealers' order flow enough to lower spreads and increase posterior value volatility. Examples where the $\mathrm{CN}$ leads to a lower spread and less efficient prices typically involve the CN dramatically increasing liquidity trader participation to overcome the effects seen in Propositions 8 (Part 1) and 15.

The second pair of rows in Table II demonstrates how the CN's effect on the spread and price efficiency depends on the longevity of the information. If $c_{o}=0$, then in the short-lived information case the spread and price efficiency with the $\mathrm{CN}$ are higher than without, but in the long-lived information case the spread and price efficiency are lower with the CN. These differences are larger when the long-lived exclusive-CN segment is not empty.

The viability of the DM is closely related to the above effects. If the spread is too wide, trading in the DM can be too expensive for liquidity traders, leaving the dealer with only the informed traders. This standard form of market failure results when the adverse selection, in terms of $\sigma_{\tilde{v}}$ and $\lambda_{I}$, is high compared to the amount of high-liquidity-preference traders. The CN can cause or prevent market failure, depending on whether or not it increases the dealer spreads. Market failure can also occur with no informed trading. If the spread increase in Proposition 15 is large enough relative to the amount of high-liquidity-preference traders, the $\mathrm{CN}$ can cause market failure even absent adverse selection. If the CN's introduction does not increase the dealer spread too much, the insiders can increase their expected gains by using the CN. Increasing the profitability of informed trading should stimulate the production of information, leading to more efficient prices.

Finally, if the CN's introduction leads to higher dealer spreads, then the lower-liquidity-preference traders, many of whom would not trade with the DM as the only option, are made better off because they get a lower-cost trading opportunity. However, the higher-liquidity-preference traders are made worse off, because they still trade in the DM, but now at a higher cost.

\section{Conclusion}

Declining technology costs and deregulation have increased the popularity of alternative trading systems such as crossing networks (CNs). One's natural inclination is to applaud the resulting combination of new technology and increased competition. However, in this paper we show that the effects of $\mathrm{CNs}$ on market performance and investor welfare are subtle and complex.

We find that the $\mathrm{CN}$ is characterized by two opposing externalities. There is the usual positive (liquidity) externality, whereby an increase in the CN's trading volume increases its liquidity, benefiting all trades and attracting additional liquidity. This also leads to a critical-mass effect: the CN must 


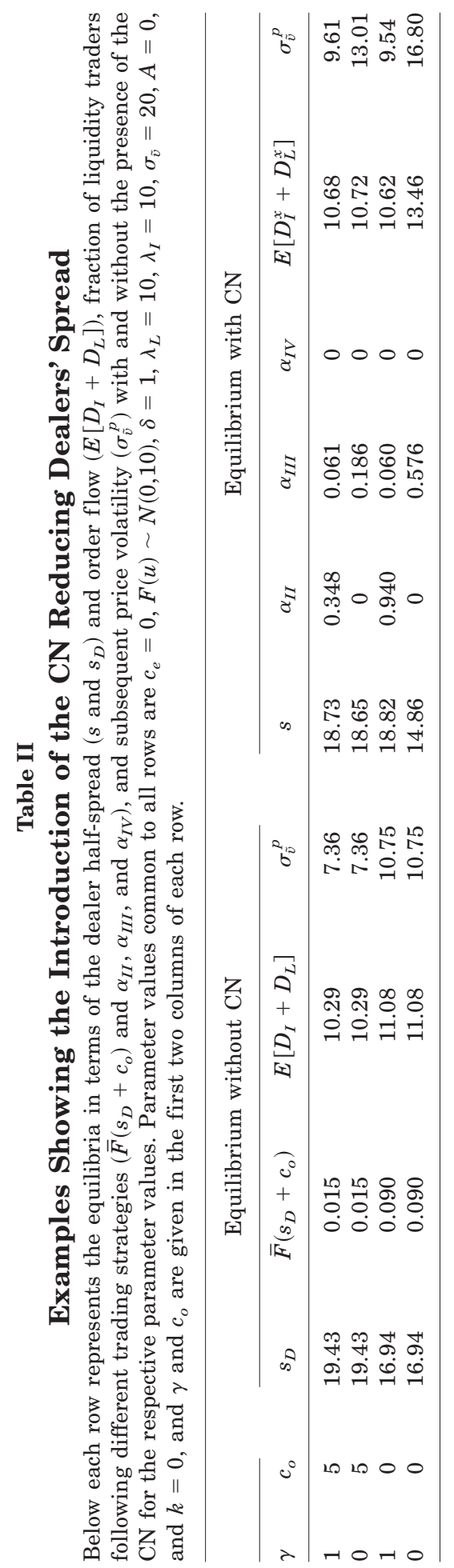


attract sufficient trading volume or it is unable to attract any order flow. We find, however, that the $\mathrm{CN}$ is also characterized by a negative externality or "crowding" effect that results from the fact that low-liquidity-preference trades compete for execution with high-liquidity-preference trades on the same side of the market. As a result, increasing the order flow going to the CN can actually reduce overall welfare. This crowding effect becomes important once the CN becomes sufficiently liquid.

When a CN competes with a dealer market (DM), its low cost attracts both new low-liquidity-preference traders and liquidity traders that would otherwise go directly to the DM. In addition, the $\mathrm{CN}$ induces traders to attempt to bypass the DM while still going to the DM when they fail to trade on the CN, and it reduces the amount of informed trading in the DM. When traders strategically use the DM as a "market of last resort," the DM becomes more risky, forcing dealers to protect themselves by widening the bid-ask spread. This reduces the attractiveness of the DM while enhancing the dealers' ability to determine more efficient subsequent prices. On the other hand, the CN can reduce adverse selection by attracting new liquidity and providing an additional venue for fundamental, value-based information trading.

How does the $\mathrm{CN}$ affect liquidity and the explicit and implicit costs borne by liquidity traders? These effects are important because changes in liquidity and bid-ask spreads affect required returns and asset values (Amihud and Mendelson (1986)). We find that the CN's effect on liquidity traders depends on the longevity of the informed traders' advantage and also on security characteristics. The $\mathrm{CN}$ allows low-liquidity-preference traders to buy an inferior service (delayed trading without an execution guarantee) at a lower cost. Enabling these traders to buy a service better suited to their needs makes them better off, but strategic use of the $\mathrm{CN}$ by some traders causes high-liquidity-preference traders to suffer when such use results in dealers widening their spreads. Overall, the introduction of a $\mathrm{CN}$ can either increase or decrease social welfare, depending on security and trader characteristics. In particular, the CN's impact is greatest on securities that have sufficient volume to enable it to achieve critical mass, but this also imposes higher costs on the dealers.

Our results also indicate that the presence of a $\mathrm{CN}$ increases the profitability of long-lived information, because patient informed traders have an additional trading venue. This should increase the production of information, increasing adverse selection. This effect, along with the strategic use of a nontransparent $\mathrm{CN}$, offers interesting parallels to previous results on intermarket trading under different levels of transparency (Chowdhry and Nanda (1991), Pagano and Röell (1996)).

The potential harmful effects of CNs can be mitigated by the use of appropriate trading rules. To combat the "crowding" effect, CNs could introduce priority pricing rules, whereby traders who seek priority of execution pay a higher price, as the new Optimark trading system attempts to do, or they could introduce price discovery. The increased adverse selection due to CNs calls for lowering informational asymmetries by changing the trading 
rules of the market, for example, by reducing anonymity, increasing transparency, and reporting order imbalances. As our results indicate, such changes must be balanced against the potential reduction in useful $\mathrm{CN}$ activity by dealers attempting to share risk (Section IV.B), large liquidity traders trying to minimize market impact, and low-liquidity-preference traders seeking a low-cost alternative. As long as CNs attracted only a small fraction of the order flow, the potentially harmful effects-and the need to address themwere small. But as $\mathrm{CNs}$ gain in popularity, ${ }^{30}$ their effects on market liquidity can become significant.

Our model addresses the impact of introducing a new market mechanism into an existing market in a particular setting. The model can also be used to explore how call markets other than CNs affect existing markets. Existing CNs are passive, with prices being derived from an existing primary market. There are other call markets, for example, the Arizona Stock Exchange, that include a pricing function, yet they are effectively passive satellites of the main market, because traders ignore their pricing mechanism and use them like a CN (Economides and Schwartz (1995)). Even the U.S. regional exchanges, which also have a pricing function, are effectively satellites of the NYSE in NYSE-listed stock (cf. Garbade and Silber (1979), Hasbrouck (1995)). Thus, our results shed light on the effects of other "satellite" markets that are effectively passive call markets.

A number of extensions of our model may be of interest. First, dealers can be assumed to have some market power, causing the introduction of the CN to reduce that power and narrow the bid-ask spread. This would provide another rationale for the development of CNs. Second, a continuous-time, dynamic multiperiod model could be constructed, leading to an additional segment of traders - those who fail to find a match in the CN and choose to wait until the next CN crossing. Another extension could give the informed traders more flexibility regarding the times and quantities of their trades and also allow liquidity traders to employ experimental trading strategies designed to detect the presence of informed traders. Finally, dealers could be allowed to reduce their risk by limiting the depth of their quotes. This would have the effect of lowering spreads, which would make the DM more attractive, but it would also eliminate certainty of execution, which in turn would make the DM less attractive.

\section{Appendix}

Proof of Proposition 1: Let $\alpha=1 / n$ be the probability that each dealer receives an order (hence $E\left[D_{I, i}+D_{L, i}\right]=\alpha \cdot E\left[D_{I}+D_{L}\right]$ ). We can write each dealer's cost, marginal cost, and average cost functions as

${ }^{30}$ In fact, our results show that even accounting for the magnitude of CNs compared to the DM is nontrivial, and published estimates that are based on transaction volumes underestimate their importance. 


$$
\begin{aligned}
C(\alpha)= & A+\alpha \cdot \sigma_{\tilde{v}} \cdot E\left[D_{I}-D_{L}\right]+k \cdot E\left[J_{D, i}{ }^{2}\right] \\
= & A+\alpha \cdot \sigma_{\tilde{v}} \cdot E\left[D_{I}-D_{L}\right]+\alpha \cdot k \\
& \cdot\left(E\left[D_{I}+D_{L}\right]+2 \cdot \alpha\left(E\left[D_{I}-D_{L}\right]^{2}+E\left[D_{I}-D_{L}\right] \cdot E\left[D_{L}\right]+E\left[D_{L}\right]^{2}\right)\right) \\
C^{\prime}(\alpha)= & \sigma_{\tilde{v}} E\left[D_{I}-D_{L}\right]+k E\left[D_{I}+D_{L}\right] \\
& +4 k \alpha\left(E\left[D_{I}\right]^{2}-E\left[D_{I}\right] E\left[D_{L}\right]+E\left[D_{L}\right]^{2}\right) \\
A C(\alpha)= & k+\sigma_{\tilde{v}} \frac{E\left[D_{I}-D_{L}\right]}{E\left[D_{I}+D_{L}\right]}+2 k \alpha^{2} \frac{E\left[D_{I}\right]^{2}-E\left[D_{I}\right] E\left[D_{L}\right]+E\left[D_{L}\right]^{2}}{\alpha E\left[D_{I}+D_{L}\right]} \\
& +\frac{A}{\alpha E\left[D_{I}+D_{L}\right]} \\
A C^{\prime}(\alpha)= & \frac{-A+2 k \alpha^{2}\left(E\left[D_{I}\right]^{2}-E\left[D_{I}\right] E\left[D_{L}\right]+E\left[D_{L}\right]^{2}\right)}{\alpha^{2} E\left[D_{I}+D_{L}\right]} \\
A C^{\prime \prime}(\alpha)= & \frac{2 A}{\alpha^{3} E\left[D_{I}+D_{L}\right]} ;
\end{aligned}
$$

The expressions for $A C(\alpha), A C^{\prime}(\alpha)$, and $A C^{\prime \prime}(\alpha)$ show that a dealer's average cost function is $U$-shaped in $\alpha$. This follows directly from the expressions for the quadratic inventory costs and the fixed costs.

Under the free entry and Bertrand competition assumptions, all dealers must operate at the cost-minimizing scale, at which $A C(\alpha)=C^{\prime}(\alpha)$, and charge the identical zero-profit spread, or additional entry will occur. The zero-profit spread is found by setting equation (3) to zero, which is equivalent to charging average cost, $A C(\alpha)$.

The efficient number of dealers is found by solving

$$
\min _{n} n \cdot\left(E\left[J_{D, i}^{2}\right]+A\right)
$$

Taking the derivative of this and solving for $n$ results in the efficient number of dealers (using the assumption that at least two dealers will enter and leaving aside any integer problems),

$$
n^{*}=\sqrt{\frac{k}{A}} \cdot \sqrt{E\left[J_{D}^{2}\right]-E\left[D_{I}+D_{L}\right]}=\frac{1}{\alpha^{*}} .
$$

Now, it is possible that there are multiple solutions to $s_{D}=A C\left(\alpha^{*}\right)=C^{\prime}\left(\alpha^{*}\right)=$ $k+\sigma_{\tilde{v}}\left(E\left[D_{I}-D_{L}\right]\right) /\left(E\left[D_{I}+D_{L}\right]\right)+2 \cdot A /\left(\alpha E\left[D_{I}+D_{L}\right]\right)$. Because $A C\left(\alpha^{*}\right)$ is convex and increasing in $s_{D}$, any solution greater than the smallest solution 
will invite entry, because it implies that additional entry is profitable. Noting that each dealer expects to receive $q=\alpha^{*} E\left[D_{I}+D_{L}\right]$ orders completes the proof. Q.E.D.

Proof of Proposition 2: The proof for the equilibrium values of $n, q$, and $s_{D}$ is identical to the proof of Proposition 1, except that the efficient number of dealers is now the solution to $\min _{n} n \cdot\left(E\left[J_{D,(i)}{ }^{2}\right]+A\right)$.

Because $E\left[J_{D,(i)}{ }^{2}\right] \leq E\left[J_{D, i}{ }^{2}\right]$, the average cost for a dealer is lower when the dealers share risk, so clearly the average cost (and zero-profit spread) at the efficient $n$ is lower. Comparing equation (4) to equation (7) shows that for a given $s_{D}, n$ is larger with risk sharing (and $n$ is decreasing in $s_{D}$ ). Thus, $n$ is larger and $s_{D}$ smaller under risk sharing. Q.E.D.

Proof of Proposition 3: The probability of having $k$ additional buyers is

$$
P\left\{N_{b}=k+1 \mid N_{b} \geq 1\right\}=\left(\frac{1}{1+\alpha \cdot \lambda}\right) \cdot\left(\frac{\alpha \cdot \lambda}{1+\alpha \cdot \lambda}\right)^{k}
$$

by the memoryless property of the geometric distribution. The probability of execution depends on both $N_{b}=k$ and on $N_{s}$ : it is $r / k+1$ if $N_{s}=r \leq k+1$, and 1 otherwise. Thus, the probability of execution conditional on $N_{b}=k$ is given by

$$
\begin{aligned}
& \sum_{r=0}^{k+1} \frac{r}{k+1} \cdot P\left\{N_{s}=r\right\}+1 \cdot P\left\{N_{s}>k+1\right\} \\
& \quad=\sum_{r=0}^{k+1} \frac{r}{k+1} \cdot\left(\frac{1}{1+\alpha \cdot \lambda}\right) \cdot\left(\frac{\alpha \cdot \lambda}{1+\alpha \cdot \lambda}\right)^{r}+\left(\frac{\alpha \cdot \lambda}{1+\alpha \cdot \lambda}\right)^{k+2} \\
& \quad=\alpha \cdot \lambda \cdot \frac{1}{k+1} \cdot\left(1-\left(\frac{\alpha \cdot \lambda}{1+\alpha \cdot \lambda}\right)^{k+1}\right)
\end{aligned}
$$

Thus, the probability of execution is

$$
\begin{aligned}
\alpha \cdot \lambda \sum_{k=0}^{\infty} \frac{\left(\frac{1}{1+\alpha \cdot \lambda}\right) \cdot\left(\frac{\alpha \cdot \lambda}{1+\alpha \cdot \lambda}\right)^{k}}{k+1} \cdot\left(1-\left(\frac{\alpha \cdot \lambda}{1+\alpha \cdot \lambda}\right)^{k+1}\right) \\
=\sum_{k=0}^{\infty} \frac{\left(\frac{\alpha \cdot \lambda}{1+\alpha \cdot \lambda}\right)^{k+1}}{k+1} \cdot\left(1-\left(\frac{\alpha \cdot \lambda}{1+\alpha \cdot \lambda}\right)^{k+1}\right) \\
=f(Q(\alpha \cdot \lambda))-f\left(Q\left((\alpha \cdot \lambda)^{2}\right)\right)
\end{aligned}
$$


where

$$
Q(\alpha \cdot \lambda)=\frac{\alpha \cdot \lambda}{1+\alpha \cdot \lambda}, \quad f(Q(\alpha \cdot \lambda))=\sum_{k=0}^{\infty} \frac{Q(\alpha \cdot \lambda)^{k+1}}{k+1}
$$

Differentiating $f(Q(\alpha \cdot \lambda))$, we have

$$
f^{\prime}(Q(\alpha \cdot \lambda))=\sum_{k=0}^{\infty} Q(\alpha \cdot \lambda)^{k}=\frac{1}{1-Q(\alpha \cdot \lambda)}
$$

whence $f(Q(\alpha \cdot \lambda))=-\log (1-Q(\alpha \cdot \lambda))$. It follows that the probability of execution is

$$
-\log (1-Q(\alpha \cdot \lambda))+\log \left(1-Q\left((\alpha \cdot \lambda)^{2}\right)\right)=\log (1+Q(\alpha \cdot \lambda))=\log \left(1+\frac{\alpha \cdot \lambda}{1+\alpha \cdot \lambda}\right)
$$

Q.E.D.

Proof of Proposition 5: The expected gross gains from trade are the expected gains from each trade times the expected number of trades, $G_{T}(\hat{u})=$ $C_{L}(\hat{u}) \cdot \delta \cdot E[u \mid u \geq \hat{u}]$. With each buyer and seller paying $c_{o}$ to submit an order to the $\mathrm{CN}, c_{e}$ for each execution, and losing $\sigma_{\tilde{v}}$ when transacting with the informed trader, the traders' expected total cost of using the $\mathrm{CN}$ is

$$
T C(\hat{u})=2 \cdot \bar{F}(\hat{u}) \cdot \lambda_{L} \cdot c_{o}+E\left[C_{L}(\hat{u})\right] \cdot c_{e}+E\left[C_{L}(\hat{u})\right] \cdot \sigma_{\tilde{v}}
$$

Total surplus is the difference between gains from trade and the cost of using the CN,

$$
\begin{aligned}
T S(\hat{u}) & =G_{T}(\hat{u})-T C(\hat{u}) \\
& =E\left[C_{L}(\hat{u})\right] \cdot\left(\delta \cdot E[u \mid u \geq \hat{u}]-c_{e}\right)-E\left[C_{I}(\hat{u})\right] \cdot \sigma_{\tilde{v}}-2 \cdot \bar{F}(\hat{u}) \cdot \lambda_{L} \cdot c_{o} .
\end{aligned}
$$

Q.E.D.

Proof of Proposition 6:

$$
E\left[C_{L}(\hat{u})\right]=\frac{\bar{F}(\hat{u}) \lambda_{L}\left(\lambda_{I}+2 \bar{F}(\hat{u}) \lambda_{L}\right)}{2 \bar{F}(\hat{u}) \lambda_{L}+\lambda_{I}+1} \leq 2 \cdot \bar{F}(\hat{u}) \cdot \lambda_{L} \cdot P(\text { trade } \mid \hat{u}),
$$

with the inequality being strict when the CN has positive order flow, $\bar{F}(\hat{u})$. $\lambda_{L}>0$. Q.E.D. 
Proof of Proposition 7: Because Proposition 7 deals only with liquidity traders, that designation will be suppressed in all references to traders here. We first show that the strategies outlined in Proposition 7 are Nash Equilibria. Assume that all other traders are following the strategies in Proposition 7 . A trader with value $u$ will receive 0 from not trading,

$$
\left(\delta \cdot u-c_{e}\right) \cdot P(\operatorname{trade} \mid \underline{\hat{u}})-\sigma_{\tilde{v}}(1-\gamma)\left(P\left(\operatorname{trade} \mid I_{0}, \underline{\hat{u}}\right)-P\left(\operatorname{trade} \mid I_{1}, \underline{\hat{u}}\right)\right)-c_{o}
$$

from using the CN exclusively,

$$
\left(\delta \cdot u-c_{e}\right) \cdot P(\operatorname{trade} \mid \underline{\hat{u}})+(1-P(\operatorname{trade} \mid \underline{\hat{u}})) \cdot(\delta \cdot u-s)-c_{o}
$$

from using the CN opportunistically, and $u-s-c_{o}$ from using the DM.

We now prove the results for the case where none of the segments are empty. This is done by comparing the adjacent strategies.

By definition of $\hat{u}_{1}$, for all values less than $\hat{u}_{1}$, equation (A12) is less than 0 , and, for all values greater than $\hat{u}_{1}$, equation (A12) is greater than 0 . This demonstrates that no trader with value below $\hat{u}_{1}$ wants to trade.

The difference between equations (A13) and (A12) is $(1-P(\operatorname{trade} \mid \underline{\hat{u}})) \cdot(\delta \cdot u-$ $s+\Delta)$, which is positive if and only if $u>(s-\Delta) / \delta=\hat{u}_{2}$. This demonstrates that using the $\mathrm{CN}$ exclusively is preferable for all traders with values less than $\hat{u}_{2}$ and using the CN opportunistically is preferable for all traders with values greater than $\hat{u}_{2}$.

The difference between $u-s-c_{o}$ and equation (13) is $u(1-\delta)-$ $\left(s-c_{e}\right) P($ trade $\mid \underline{\hat{u}})$, which is greater than zero if and only if $u>\left[\left(s-c_{e}\right) /\right.$ $(1-\delta)] P($ trade $\mid \underline{\hat{u}})=\hat{u}_{3}$. This shows that going directly to the DM is preferable for traders with values greater than $\hat{u}_{3}$ and using the CN opportunistically is preferable for traders with values less than $\hat{u}_{3}$.

Taken together, these comparisons prove the desired result. The cases when some of the segments are empty are similar. Q.E.D.

Proof of Proposition 8: When the informed trader's information is short lived, the expected number of orders on each side of the $\mathrm{CN}$ is geometrically distributed with expected value $E\left[C_{I}^{S}\right]=E\left[C_{L}^{S}\right]=\left(\alpha_{I I}+\alpha_{I I I}\right) \lambda_{L}$, and the probability that an order going to the $\mathrm{CN}$ is opportunistic (exclusive) is $\alpha_{C O}^{S}=\alpha_{\mathrm{III}} /\left(\alpha_{\mathrm{III}}+\alpha_{\mathrm{II}}\right)\left[\alpha_{C E}^{S}=\alpha_{\mathrm{II}} /\left(\alpha_{\mathrm{III}}+\alpha_{\mathrm{II}}\right)\right]$. The expected number of trades that execute on the $\mathrm{CN}$ is $E\left[C_{T}^{S}\right]=E\left[C_{I}^{S}\right] \cdot E\left[C_{L}^{S}\right] /\left(E\left[C_{I}^{S}+C_{L}^{S}\right]+1\right)$.

To calculate the expected overall inventory imbalance, we must take into account the different orders. Let $d_{I}\left(d_{L}\right)$ be the realized number of orders going to the $\mathrm{CN}$ on the informed (liquidity) side, $I$ be the realized number of informed orders, $c_{I}\left(c_{L}\right)$ be the realized number of orders going to the CN on the informed (liquidity) side, and $c_{d}$ be the realized number of orders that did not trade on the $\mathrm{CN}$ that go to the dealer market (all of which are on the informed (liquidity) side if $c_{I}>c_{L}\left(c_{I}<c_{L}\right)$ ) which is binomially distributed 
(conditional on $c_{I}$ and $c_{L}$ ) with parameters $\left|c_{I}-c_{L}\right|$ and $\alpha_{C O}$. The distributions of $d_{I}, d_{L}$, and $I$ conditional on $c_{I}$ and $c_{L}$ can be found using Bayes' rule. With these order flows and omitting the tedious repeated applications of the properties of the geometric and binomial distributions, the expected order imbalance squared in the DM is

$$
\begin{aligned}
E\left[J_{S}^{2}\right]= & \sum_{c_{I}=0}^{\infty} \sum_{c_{L}=0}^{c_{I}-1} \sum_{I=0}^{\infty} \sum_{d_{I}=0}^{\infty} \sum_{d_{L}=0}^{\infty} \sum_{c_{d}=0}^{c_{I}-c_{L}}\left(d_{I}-d_{L}+c_{d}+I\right)^{2} P\left(c_{d} \mid c_{I}, c_{L}\right) P\left(d_{I} \mid c_{I}\right) \\
& \times P\left(d_{L} \mid c_{L}\right) P\left(I \mid c_{I}\right) P\left(c_{L}\right) P\left(c_{I}\right) \\
& +\sum_{c_{I}=0}^{\infty} \sum_{c_{L}=c_{I}}^{\infty} \sum_{I=0}^{\infty} \sum_{d_{I}=0}^{\infty} \sum_{d_{L}=0}^{\infty} \sum_{c_{d}=0}^{c_{L}-c_{I}}\left(d_{L}-d_{I}+c_{d}-I\right)^{2} P\left(c_{d} \mid c_{I}, c_{L}\right) \\
& \times P\left(d_{I} \mid c_{I}\right) P\left(d_{L} \mid c_{L}\right) P\left(I \mid c_{I}\right) P\left(c_{L}\right) P\left(c_{I}\right) \\
= & E\left[J_{D}{ }^{2}\right]-2 \cdot \alpha_{C O}^{S} \cdot \alpha_{C E}^{S} \cdot E\left[C_{T}^{S}\right],
\end{aligned}
$$

demonstrating how trades between opportunistic traders and exclusive liquidity traders in the $\mathrm{CN}$ reduce the dealers' risk in an amount proportional to the trading in the $\mathrm{CN}$. With $n$ symmetric dealers competing, the calculation for dealer $i$ 's expected inventory risk is similar to equation (A14) with dealer $i$ 's inventory being binomially distributed conditional on the total imbalance,

$$
E\left[{J_{S, i}}^{2}\right]=E\left[{J_{D, i}}^{2}\right]-2\left(\frac{n-1}{n^{2}}\right) \alpha_{C O}^{S} \cdot E\left[C_{T}^{S}\right]-\frac{2}{n} \cdot \alpha_{C O}^{S} \cdot \alpha_{C E}^{S} \cdot E\left[C_{T}^{S}\right]
$$

In addition to the benefits of trades between exclusive and opportunistic traders, the second term of equation (A15) shows how the CN provides risksharing benefits to the dealers. The number of orders dealers expect to receive on the informed side, $D_{I}^{S}$, and on the liquidity side, $D_{L}^{S}$, are

$$
E\left[D_{I}^{S}\right]=E\left[D_{I}\right]-\alpha_{C O}^{S} \cdot E\left[C_{T}^{S}\right] \text { and } E\left[D_{L}^{S}\right]=E\left[D_{L}\right]-\alpha_{C O}^{S} \cdot E\left[C_{T}^{S}\right]
$$

Thus, the loss of orders from trades that execute in the $\mathrm{CN}$ is twice the fraction of orders in the $\mathrm{CN}$ that are opportunistic times the expected number of CN trades, $E\left[D_{I}+D_{L}\right]-E\left[D_{I}^{S}+D_{L}^{S}\right]=2 \cdot \alpha_{C O}^{S} \cdot E\left[C_{T}^{S}\right]$. Although the order flow going to the DM is reduced by opportunistic trades being executed on the CN, the expected order imbalance is not: $E\left[D_{I}^{S}-D_{L}^{S}\right]=\lambda_{I}$.

Overall, the use of the CN provides some risk reduction on opportunistic-CN orders through both risk sharing and their trading with exclusive-CN orders. The CN also reduces the dealers' order flow without reducing the adverse selection. This latter effect is always stronger, as shown by the following lemma which will be useful in proving subsequent results and is part of Proposition 10. 
Lemma 2: If the informed traders have short-lived information, the dealer spread is higher than in the no-CN case and the increase in spread is increasing in the amount of CN liquidity trading, $\alpha_{I I}$ and $\alpha_{I I I}$. If there is no informed trading, $\lambda_{I}=0$, then the spread is increasing in the amount of opportunistic-CN liquidity trading, $\alpha_{I I I}$.

Proof: In this proof we use equations (25) and (26) with $\gamma=1$. We first show the result for $\alpha_{I I}$. It is straightforward to verify that $\left(\partial E\left[D_{I}^{S}+\right.\right.$ $\left.\left.D_{L}^{S}\right]\right) / \partial \alpha_{I I}<0$ and $E\left[D_{I}^{S}+D_{L}^{S}\right]$ is independent of $\alpha_{I I}$, so clearly the first term of equation (26) is increasing in $\alpha_{I I}$. It can also be verified that $q$ is decreasing in $\alpha_{I I}$, implying that the second term of equation (26) is increasing in $\alpha_{I I}$. Because the third term of equation (26) is simply $k$ (when $\gamma=1$ ), the spread is increasing in $\alpha_{I I}$. That the spread is greater than in the no-CN case follows from the loss of order flow and the fact that $n$ is greater with the $\mathrm{CN}$ (due to risk sharing via the $\mathrm{CN}$ ).

The difference in the adverse-selection component of the spread between the $\mathrm{CN}$ and no-CN cases is increasing in $\alpha_{I I I}$ because the fraction of the opportunistic orders going to the $\mathrm{DM}$ when the $\mathrm{CN}$ is present is decreasing in $\alpha_{I I I}$ (because the $\mathrm{CN}$ is becoming more liquid). It is straightforward to verify that the inventory and fixed-cost components of the spread are increasing in $\alpha_{I I I}$. This fact also guarantees that the spread is increasing in $\alpha_{I I I}$ when there is no informed trading. Q.E.D. of Lemma

When the informed trader's information is long lived, the expected number of orders on the informed (liquidity) side of the market going to the CN is geometrically distributed with expected value $E\left[C_{I}^{L}\right]=\left(\alpha_{I I}+\alpha_{I I I}\right) \lambda_{L}+\lambda_{I}$ $\left(E\left[C_{L}^{L}\right]=\left(\alpha_{I I}+\alpha_{I I I}\right) \lambda_{L}\right.$, resp.). The probability that an order on the informed (liquidity) side going to the $\mathrm{CN}$ is opportunistic is $\alpha_{C O, I}^{L}=\left(\alpha_{I I I} \cdot \lambda_{L}+\right.$ $\left.\lambda_{I}\right) /\left[\left(\alpha_{I I I}+\alpha_{I I}\right) \lambda_{L}+\lambda_{I}\right]\left[\alpha_{C O, L}^{L}=\alpha_{\mathrm{III}} /\left(\alpha_{\mathrm{III}}+\alpha_{\mathrm{II}}\right)\right]$ with the exclusive probability, $\alpha_{C E, I}^{L}\left(\alpha_{C E, L}^{L}\right)$, being the complement. The expected number of trades that execute on the $\mathrm{CN}$ is $E\left[C_{T}^{L}\right]=E\left[C_{I}^{L}\right] \cdot E\left[C_{L}^{L}\right] /\left(E\left[C_{I}^{L}\right]+E\left[C_{L}^{L}\right]+1\right)$. The expected overall order imbalance squared when the informed trader's information is long-lived is similar to equation (A14) with the informed trading in the CN opportunistically,

$$
\begin{aligned}
E\left[J_{L}{ }^{2}\right]= & E\left[J_{D}{ }^{2}\right]-E\left[C_{T}^{L}\right] \cdot\left(\alpha_{C O, L}^{L} \cdot \alpha_{C E, I}^{L}+\alpha_{C O, L}^{L} \cdot \alpha_{C E, I}^{L}+\frac{2 \cdot \lambda_{I}^{2}}{E\left[C_{I}^{L}\right]}\right) \\
& +\frac{\alpha_{I V}}{\alpha_{I I}} \cdot\left(\frac{\lambda_{I} \cdot \alpha_{C E, L}^{L} \cdot E\left[C_{T}^{L}\right]}{E\left[C_{I}^{L}\right]}\right)^{2},
\end{aligned}
$$

which indicates the two opposing effects of the CN's operations. First, as with short-lived information, opportunistic traders trading with exclusive liquidity traders in the $\mathrm{CN}$ reduce the risk they pose to the dealers, except that here the informed's trading is included in the opportunistic-CN orders, further reducing the risk. Second, the informed traders going to the $\mathrm{CN}$ 
allows the covariance of the exclusive and dealer liquidity traders to increase the dealers' risk. With $n$ dealer competing, dealer $i$ 's expected inventory risk is

$$
\begin{aligned}
E\left[J_{L, i}{ }^{2}\right]= & E\left[J_{D, i}{ }^{2}\right]-2\left(\frac{n-1}{n^{2}}\right) \alpha_{C O, I}^{L} \cdot \alpha_{C O, L}^{L} \cdot E\left[C_{T}^{L}\right] \\
& -\frac{E\left[C_{T}^{L}\right]}{n} \cdot\left(\alpha_{C O, L}^{L} \cdot \alpha_{C E, I}^{L}+\alpha_{C O, L}^{L} \cdot \alpha_{C E, I}^{L}+\frac{2 \cdot \lambda_{I}^{2}}{n \cdot E\left[C_{I}^{L}\right]}\right) \\
& +\frac{\alpha_{I V}}{\alpha_{I I}} \cdot\left(\frac{\lambda_{I} \cdot \alpha_{C E, L}^{L} \cdot E\left[C_{T}^{L}\right]}{n \cdot E\left[C_{I}^{L}\right]}\right)^{2} .
\end{aligned}
$$

Similar to the short-lived information case, the second term of equation (A18) represents the risk-sharing benefits from orders going through the $\mathrm{CN}$, and the final two terms are related to the change in risk because opportunistic orders can trade with the exclusive-CN orders. The number of orders the dealers expect to receive on the informed side, $D_{I}^{L}$, and on the liquidity side, $D_{L}^{L}$, are

$$
E\left[D_{I}^{L}\right]=E\left[D_{I}\right]-\alpha_{C O, I}^{L} \cdot E\left[C_{T}^{L}\right] \quad \text { and } \quad E\left[D_{L}^{L}\right]=E\left[D_{L}\right]-\alpha_{C O, L}^{L} \cdot E\left[C_{T}^{L}\right]
$$

which together with equation (A16) shows that the dealers lose orders from trades that execute in the CN: $\left.\gamma \cdot E\left[D_{I}^{S}\right]+(1-\gamma) E\left[D_{I}^{L}\right]\right) \leq E\left[D_{I}\right]$ and $\left.\gamma \cdot E\left[D_{L}^{S}\right]+(1-\gamma) E\left[D_{L}^{L}\right]\right) \leq E\left[D_{L}\right]$. However, the expected order imbalance

$$
E\left[D_{I}^{L}-D_{L}^{L}\right]=\lambda_{I}\left(1-\frac{\alpha_{C E, L}^{L} \cdot E\left[C_{T}^{L}\right]}{E\left[C_{I}^{L}\right]}\right)
$$

is decreased by the informed trading on the $\mathrm{CN}$, with the percentage decrease being the expected amount of $\mathrm{CN}$ trades on the liquidity side divided by the expected number of $\mathrm{CN}$ orders on the informed side. Q.E.D.

Proof of Proposition 9: The proof is the same as that of Proposition 1, modified to take into account the CN's impact on the order flow, included in the proof of Proposition 8, and the dealers' expected costs and order flows are the weighted averages from equations (A14)-(A20). The change in the inventory risk changes the dealers' efficient scale. In particular, the additional terms - those beyond the baseline case - that are quadratic in $1 / n$ when the information is long lived, from equation (A18), are

$$
\psi^{L}=2 \cdot E\left[C_{T}^{L}\right]\left(\alpha_{C O, I}^{L} \cdot \alpha_{C O, L}^{L}+\frac{\lambda_{I}^{2}}{E\left[C_{I}^{L}\right]}\right)-\frac{\alpha_{I V}}{\alpha_{I I}} \cdot\left(\frac{\lambda_{I} \cdot \alpha_{C E, L}^{L} \cdot E\left[C_{T}^{L}\right]}{E\left[C_{I}^{L}\right]}\right)^{2}
$$


and when the information is short lived, from equation (A18), the terms are

$$
\psi^{S}=2 \cdot \alpha_{C O}^{S} \cdot \alpha_{C E}^{S} \cdot E\left[C_{T}^{S}\right]
$$

Similarly the expected order flow and competitive spread can be calculated as in the proof of Proposition 1 with the order flows and costs given by equations (A14)-(S20). Q.E.D.

Proof of Proposition 10: If the information is short lived, the desired results follow from Lemma 2. Proposition 11 shows that when $\alpha_{I I}=0$, the spread is increasing in $\gamma$, completing the proof. Q.E.D.

Proof of Proposition 11: If $\alpha_{I I}=0$, it is straightforward to show that for a given half-spread, the number of dealers is decreasing in $\gamma$. If $\alpha_{I I}=0$, $E\left[D_{I}^{S}+D_{L}^{S}\right]-E\left[D_{I}^{L}+D_{L}^{L}\right]=\left[2 \cdot \alpha_{I I I} \cdot \lambda_{I} \cdot \lambda_{L} \cdot\left(1+\alpha_{I I I} \cdot \lambda_{L}\right)\right] /[(1+$ $\left.\left.2 \cdot \alpha_{I I I} \cdot \lambda_{L}\right)\left(1+\lambda_{I}+2 \cdot \alpha_{I I I} \cdot \lambda_{L}\right)\right]>0$, so the total number of orders going to the $\mathrm{CN}$ is increasing in $\gamma$. This, together with the fact that the number of dealers is decreasing in $\gamma$, implies that the order flow per dealer, $q$, is increasing in $\gamma$. If $\alpha_{I I}=0, E\left[D_{I}^{S}-D_{L}^{S}\right]=E\left[D_{I}^{L}-D_{L}^{L}\right]=\lambda_{\mathrm{I}}$ and

$$
s=\sigma_{\tilde{v}} \cdot \frac{\gamma \cdot E\left[D_{I}^{S}-D_{L}^{S}\right]+(1-\gamma) E\left[D_{I}^{L}-D_{L}^{L}\right]}{\gamma \cdot E\left[D_{I}^{S}+D_{L}^{S}\right]+(1-\gamma) E\left[D_{I}^{L}+D_{L}^{L}\right]}+\frac{2 \cdot A}{q}+k .
$$

The first term of equation (A23) is decreasing in $\gamma$ because the denominator is increasing and the numerator is constant. The second term of equation (A23) is decreasing in $\gamma$ because $q$ is increasing in $\gamma$. Q.E.D.

Proof of Proposition 14: The ratio of the expected number of trades to the expected number of orders is

$$
\frac{2 \cdot\left((1-\gamma) \cdot E\left[C_{T}^{L}\right]+\gamma \cdot E\left[C_{T}^{S}\right]\right)}{(1-\gamma) \cdot E\left[C_{I}^{L}+C_{L}^{L}\right]+\gamma \cdot E\left[C_{I}^{S}+C_{L}^{S}\right]}
$$

It is straightforward to verify that this expression is less than or equal to $\frac{1}{2}$, and the smaller the liquidity order flow to the $\mathrm{CN}$, the lower the ratio. Q.E.D.

Proof of Proposition 15: If $\lambda_{I}=0$, the distinction between short- and longlived information is irrelevant. Noting that the spread is (weakly) decreasing in $\alpha_{I V}$ (if $\alpha_{I I}=\alpha_{I I I}=0$, the spread is constant in $\alpha_{I V}$ ), we can apply Lemma 2 to prove the desired result. Q.E.D.

Proof of Proposition 16: If $\gamma=1$, a trader with $u=\hat{u}_{2}$ receives positive surplus from using the CN exclusively; hence we know that $\alpha_{I I}>0$ and equation (20) applies. With $c_{o}=0$, this guarantees that $\hat{u}_{2} \geq s_{D}+c_{o}$. Hence, no opportunistic-CN trading is "new" (i.e., comes from traders who would not have traded in the DM in the dealer-only case). With this, along with the observations that opportunistic-CN trades are more costly to serve than dealer 
trades, we can apply Lemma 2 to demonstrate that spreads are higher. With short-lived information all informed orders go the dealers. This along with the fact that the number of liquidity orders decreases guarantees that the dealers' prices must be more efficient. Q.E.D.

\section{REFERENCES}

Admati, Anat, and Paul Pfleiderer, 1988, A theory of intraday patterns: Volume and price variability, Review of Financial Studies 1, 3-40.

Amihud, Yakov, and Haim Mendelson, 1980, Dealership market: Market making with inventory, Journal of Financial Economics 8, 31-53.

Amihud, Yakov, and Haim Mendelson, 1982, Asset price behavior in a dealership market, Financial Analyst Journal 38, 50-59.

Amihud, Yakov, and Haim Mendelson, 1986, Asset pricing and the bid-ask spread, Journal of Financial Economics 17, 223-249.

Amihud, Yakov, Haim Mendelson, and Beni Lauterbach, 1997, Market microstructure and securities values: Evidence from the Tel Aviv stock exchange, Journal of Financial Economics $45,365-390$.

Battalio, Robert, 1997, Third market broker-dealers: Cost competitors or cream skimmers? An empirical analysis, Journal of Finance 52, 341-352.

Battalio, Robert, Jason Greene, and Robert Jennings, 1997, Do competing specialists and preferencing dealers affect market quality? Review of Financial Studies 10, 969-993.

Bernhardt, Dan, Burton Hollifield, and Eric Hughson, 1995, Investment and insider trading, Review of Financial Studies 8, 501-543.

Biais, Bruno, 1993, Price formation and equilibrium liquidity in fragmented and centralized markets, Journal of Finance 35, 157-185.

Brown, David, and Zhi Zhang, 1997, Market orders and market efficiency, Journal of Finance $52,277-308$.

Chowdhry, Bhagwan, and Vikram Nanda, 1991, Multimarket trading and market liquidity, Review of Financial Studies 3, 483-511.

Christie, William, and Paul Schultz, 1994, Why do Nasdaq market makers stop avoiding oddeighth quotes? Journal of Finance 49, 1813-1840.

Christie, William, Jeffrey Harris, and Paul Schultz, 1994, Why did Nasdaq market makers avoid odd-eighth quotes? Journal of Finance 49, 1841-1860.

Cohen, Kalman, Steven Maier, Robert Schwartz, and David Whitcomb, 1978, Limit orders, market structure, and the returns generation process, Journal of Finance 33, 723-736.

Cohen, Kalman, Steven Maier, Robert Schwartz, and David Whitcomb, 1981, Transaction costs, order placement, and existence of the bid-ask spread, Journal of Political Economy 89, 287-305.

Easley, David, and Maureen O'Hara, 1987, Price, trade size, and information in securities markets, Journal of Financial Economics 19, 69-90.

Easley, David, and Maureen O'Hara, 1992, Time and the process of security price adjustment, Journal of Finance 57, 577-606.

Economides, Nicholas, and Robert Schwartz, 1995, Electronic call market trading, Journal of Portfolio Management 21, 10-18.

Garbade, Kenneth, and William Silber, 1979, Dominant and satellite markets: A study of duallytraded securities, Review of Economics and Statistics 61, 455-460.

Garman, Mark, 1976, Market microstructure, Journal of Financial Economics 3, 257-275.

Glosten, Lawrence, 1994, Is the electronic open limit order book inevitable? Journal of Finance $49,1127-1161$.

Glosten, Lawrence, and Paul Milgrom, 1985, Bid, ask and transaction prices in a specialist market with heterogeneously informed traders, Journal of Financial Economics 14, 71-100.

Grossman, Sanford, and Merton Miller, 1988, Liquidity and market structure, Journal of Finance 43, 617-633. 
Hasbrouck, Joel, 1995, One security, many markets: Determining the contributions to price discovery, Journal of Finance 50, 1175-1199.

Ho, Thomas, and Richard Macris, 1985, Dealer market structure and performance; in Yakov Amihud, Thomas Ho, and Robert Schwartz, eds.: Market Making and the Changing Structure of the Securities Industry (Heath, Lexington, MA).

Ho, Thomas, and Hans Stoll, 1981, Optimal dealer pricing under transaction and return uncertainty, Journal of Financial Economics 9, 47-73.

Ho, Thomas, and Hans Stoll, 1983, The dynamics of dealer markets under competition, Journal of Finance 38, 1053-1074.

Katz, Michael, and Carl Shapiro, 1985, Network externalities, competition, and compatibility, American Economic Review 75, 424-440.

Madhavan, Ananth, 1992, Trading mechanisms in securities markets, Journal of Finance 48, 607-641.

Madhavan, Ananth, and Seymour Smidt, 1991, A Bayesian model of intraday specialist pricing, Journal of Financial Economics 30, 99-134.

Madhavan, Ananth, and Seymour Smidt, 1993, An analysis of changes in specialist inventories and quotations, Journal of Finance 48, 1595-1628.

Mendelson, Haim, 1982, Market behavior in a clearing house, Econometrica 50, 1505-1524.

Mendelson, Haim, 1985, Random competitive exchange: Price distribution and gains from trade, Journal of Economic Theory 37, 254-280.

Mendelson, Haim, 1987, Consolidation, fragmentation, and market performance, Journal of Financial and Quantitative Analysis 22, 187-207.

Mildenstein, Eckart, and Harold Schleef, 1983, The optimal pricing policy of a monopolistic marketmaker in the equity market, Journal of Finance 38, 218-231.

Pagano, Marco, 1989, Trading volume and asset liquidity, Quarterly Journal of Economics 104, $255-274$.

Pagano, Marco, and Ailisa Röell, 1996, Transparency and liquidity: A comparison of auction and dealer markets with informed trading, Journal of Finance 51, 579-611.

Parlour, Christine, and Duane Seppi, 1998, Liquidity-based competition for order flow, Working paper, Carnegie-Mellon University.

Reiss, Peter, and Ingrid Werner, 1998, Does risk sharing motivate interdealer trading? Journal of Finance 53, 1657-1703.

Securities and Exchange Commission, Regulation of exchanges and alternative trading systems, Release Number 34-40760, December 8, 1998.

Seppi, Duane, 1997, Liquidity provision with limit orders and a strategic specialist, Review of Financial Studies 10, 103-150.

Stoll, Hans, 1978, The supply of dealer services in securities markets, Journal of Finance 33, 1133-1151. 
2116 